\title{
ELENA MOK
}

\section{CORONIAL LAW REFORM THROUGH THE LENS OF THERAPEUTIC JURISPRUDENCE - HARNESSING THE FULL POTENTIAL OF CORONERS' RECOMMENDATIONS}

\author{
LLM RESEARCH PAPER \\ LAWS 513: LAW AND MEDICINE
}

FACULTY OF LAW

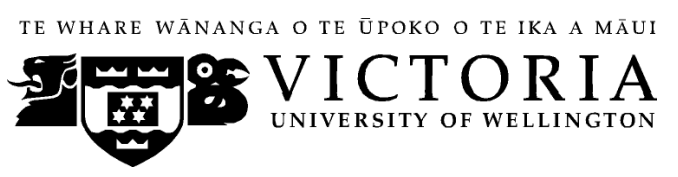

2013 


\section{Contents}

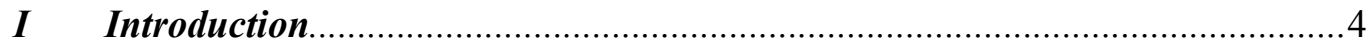

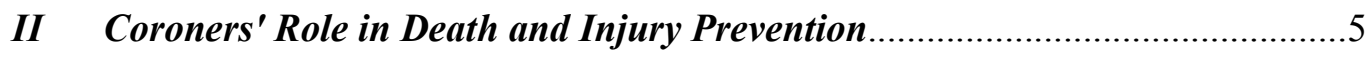

III Current Implementation of Recommendations..................................................

A Power to Enforce Recommendations and Factors Influencing

Implementation ..................................................................................

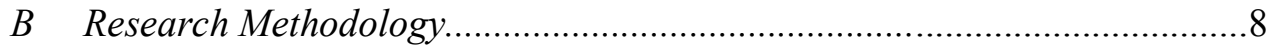

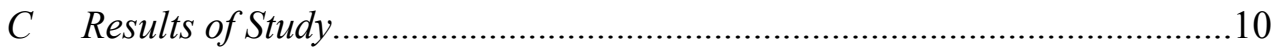

IV Issues Surrounding Coroners' Recommendations.........................................13

A Impractical and Overly Broad Recommendations......................................13

B Implicit Apportionment of Blame...............................................................19

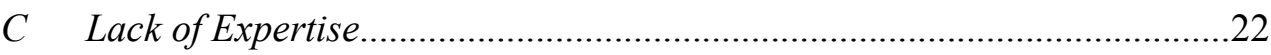

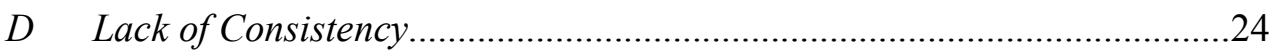

E Overlap with Other Investigating Authorities.........................................25

F 'Stale' Recommendations - Delays in Completion of Findings..................27

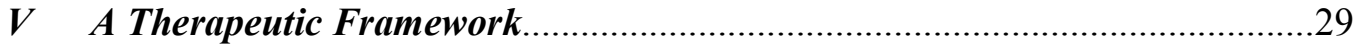

A Principles of Therapeutic Jurisprudence ....................................................29

B Applicability of Therapeutic Jurisprudence to the Coronial Process...........30

C Some Criticisms of Therapeutic Jurisprudence............................................34

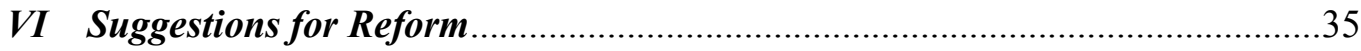

A Better Guidance for Formulating Recommendations...................................35

$B \quad$ Increased Collaboration with Agencies, Organisations and Family

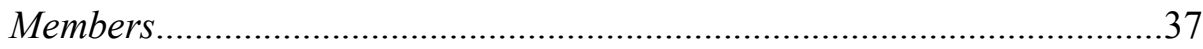

C Mandatory Response Provisions..............................................................45

D Restorative Justice Conferences.............................................................47

E Refining the Coroner's Investigative Function...........................................49

F Improving Transparency and Data Collection Processes..........................54

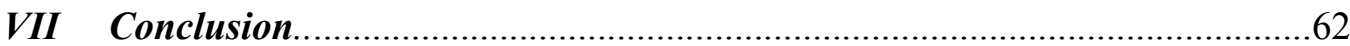

VIII Appendix One - Tables and Charts Relating to Findings of Study ...............64

IX Appendix Two-Flowcharts of the Coronial Process................................... 71

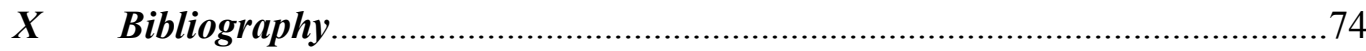




\section{Abstract}

The ability of coroners to make recommendations to various agencies and organisations is inextricably linked with the coroner's emerging role in death and injury prevention. Yet, there is no legal obligation in New Zealand for agencies and organisations to respond to, or implement, proposed changes, which has led to claims that recommendations are merely being overlooked. However, concerns have also been raised about the quality of some recommendations, especially whether coroners have sufficient expertise to be proposing wide-ranging legal and policy reforms. This paper analyses the extent to which recommendations are being implemented by the agencies and organisations to whom they are directed, and addresses whether the criticisms levelled at recommendations are valid. It is contended that, in considering reforms to the coronial process, the principles of therapeutic jurisprudence should be applied so as to maximise the therapeutic potential of recommendations for families and the wider community. Ultimately, it is concluded that greater transparency and accountability is needed in coronial processes to fully harness the preventive and therapeutic potential of coroners' recommendations.

\section{Word length}

The text of this paper (excluding abstract, table of contents, footnotes, bibliography and appendices) comprises approximately 15,326 words.

\section{Subjects and Topics}

Coroners Act 2006

Coronial recommendations

Therapeutic Jurisprudence 


\section{Introduction}

Although most deaths do not require investigation, occasionally state involvement is needed to ascertain the cause or manner of death. ${ }^{1}$ The primary role of coroners is to establish the cause and circumstances of sudden or unexplained deaths and deaths in other special circumstances. ${ }^{2}$ Unlike other investigations into accidents and deaths, coroners' investigations focus on the person who has died and the circumstances of their death. This provides clarity for the family of the deceased and assures the community that no death will be "overlooked, concealed or ignored". 3

Despite this, a separate and wider function, "the vindication of the public interest in the prevention of death by the public exposure of conditions that threaten life", has become increasingly significant and, in some cases, just as crucial as the investigation of the facts surrounding individual deaths. ${ }^{4}$ Coroners' ability to make recommendations to government agencies and other organisations for the purpose of preventing deaths in similar circumstances is inextricably linked with this role. However, the extent to which coroners' recommendations contribute to positive health and safety outcomes is uncertain. Further, numerous concerns have been raised, both in New Zealand and overseas, regarding the quality and consistency of recommendations, the sources of expertise coroners draw on and the lack of involvement of key parties before recommendations are released. ${ }^{5}$ As a result, the Minister for Courts has proposed a number of amendments to the Coroners Act 2006 following a targeted review by the Ministry of Justice (MOJ review). The coroner's recommendation-making power will be the most significant area of reform. ${ }^{6}$

This paper addresses the issues surrounding coroners' recommendations and discusses whether reform in this area is necessary. Part II provides an overview of the coroner's

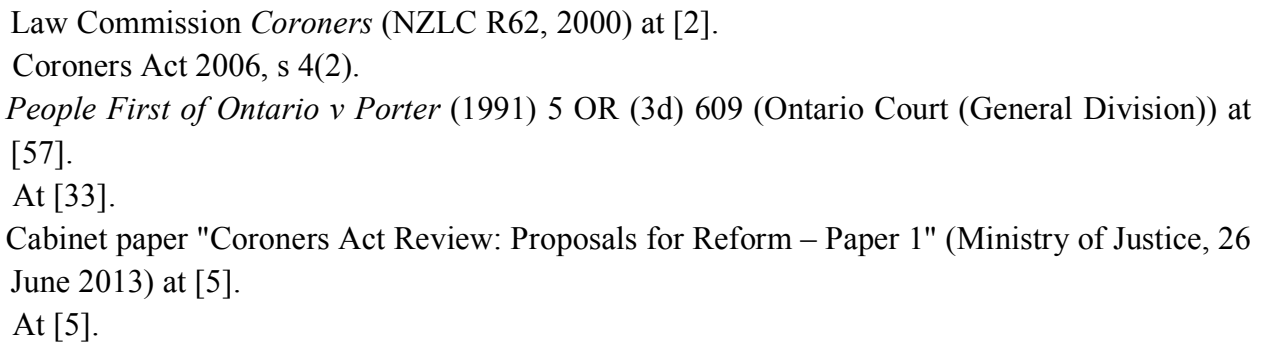


role in death and injury prevention. Part III discusses the results of a small-scale study undertaken as part of this paper to examine the nature and frequency of coroners' recommendations in New Zealand, as well as the various factors which influence the implementation of recommendations by the agencies and organisations to whom they are directed. Part IV examines whether the criticisms levelled at recommendations are valid. In Part V it is contended that the principles of therapeutic jurisprudence should be applied in considering modifications to the coronial process. Finally, Part VI proposes various reforms that, if implemented, would not only improve the coroner's preventive function, but would also enhance the therapeutic potential of the coronial process.

\section{Coroners' Role in Death and Injury Prevention}

One of the most enduring features of the coronial process has been its ability to adapt and evolve in response to community needs. ${ }^{7}$ Early New Zealand coronial practice under the Coroners Ordinance 1846 was largely modelled on the English system. ${ }^{8}$ Initially, coroners' work was intimately connected with the criminal law, as coroners' inquests were an important mechanism for determining whether deaths were criminal or not. ${ }^{9}$ If a coroner's jury delivered a verdict of murder or manslaughter against a person, this had the effect of an indictment: the coroner was obliged to issue a warrant for the apprehension of the accused and to commit him or her to prison. ${ }^{10}$ However, the subsequent establishment of an effective police force rendered this function largely redundant, ${ }^{11}$ and the Criminal Code Act 1893 explicitly stated that no person should be tried on a coroner's inquisition. ${ }^{12}$ Juries were eventually abolished in $1951 . .^{13}$

\footnotetext{
7 Ian Freckelton and David Ranson Death Investigation and the Coroner's Inquest (Oxford University Press, Melbourne, 2006) at 752.

$8 \quad$ Freckelton and Ranson, above n 7, at 28.

9 Death Certification and Investigation in England, Wales and Northern Ireland, Report of a Fundamental Review (HMSO, Cm 5831, 2003) at 87.

$10 \quad$ Freckelton and Ranson, above n 7, at 30.

11 At 30 .

12 See also Coroners Act 1908, s 6.

13 Coroners Act 1951, s 13(1).
} 
The coroner's inquest has since become an inquisitorial fact-finding exercise, rather than a method of apportioning guilt, ${ }^{14}$ and coroners are expressly precluded from determining any kind of liability. ${ }^{15}$ With the exclusion of coroners "from anything resonant of criminal adjudication", ${ }^{16}$ and the proliferation of public bodies with death investigation functions, there has been a growing awareness that coronial investigations must be able to go beyond cause of death if they are to serve a "useful social function". ${ }^{17}$ The gradual erosion of the coroner's traditional role has even caused some to question whether coroners have become an "anachronism worth retaining". ${ }^{18}$ However, the role of coroners in preventing future deaths has the ability to revitalise the coronial process and give it a new sense of relevance. ${ }^{19}$

The revitalisation of the coroner's role coincided with the public health movement in the 1980s, which resulted in an increasingly sophisticated exploration of the relationship between social and environmental factors in health, "with the aim of managing problems identified as posing a health threat to the community". ${ }^{20}$ Public health research has revealed that a proper appraisal of supposedly insignificant incidents can reveal, and subsequently remove or mitigate, the risk of future deaths. ${ }^{21}$ Modern injury prevention theories stress the importance of viewing death and injury as a collective public health problem, as opposed to unpredictable and isolated occurrences. ${ }^{22}$ Every death represents the "tip of an iceberg of injuries", ${ }^{23}$ so when patterns of injury surface, this is indicative of a social problem. ${ }^{24}$ Accordingly, a broad-based strategy not only has the potential to forestall deaths, but to alleviate health and safety risks more generally. ${ }^{25}$ Further, the causes of fatalities are often

\footnotetext{
14 Law Commission Coroners, above n 1, at [6].

15 Coroners Act 2006, s 57(1).

$16 \quad$ Freckelton and Ranson, above $\mathrm{n} 7$, at 716.

17 Orchard v Osborne \& Anor HC Auckland M101-96, 19 July 1996 at 7 per Paterson J.

$18 \quad$ Freckelton and Ranson, above n 7, at 714.

19 At 756.

$20 \quad$ At 719.

21 Law Commission Coroners, above n 1, at [10].

22 James Harrison and Jerry Moller "Learning from experience: towards prevention" in Hugh Selby (ed) The Inquest Handbook (Federation Press, New South Wales, 1998) 208 at 208.

23 Boronia Halstead "Coroners' recommendations following deaths in custody" in Hugh Selby (ed) The Inquest Handbook (Federation Press, New South Wales, 1998) 186 at 187.

$24 \quad$ Harrison and Moller, above n 22, at 208.

$25 \quad$ Halstead, above n 23, at 187.
} 
multi-faceted and call for a multi-disciplinary approach. ${ }^{26}$ An effective preventive strategy requires an understanding of the way in which an entire system of influences operates, as attributing responsibility to one or two parts of the system is usually ineffective in solving systemic problems. ${ }^{27}$

Deaths without known cause, suicides, unnatural or violent deaths, and deaths that occurred during medical operations or in official custody or care must all be reported to the coroner. ${ }^{28}$ The wide variety of deaths that come within coroners' purview means that they are well placed to acquire a pattern-informed viewpoint of issues concerning death and injury. ${ }^{29}$ The coroner's potential role in preventing injury and death has consequently become a prominent feature in the evolution of the coronial process in New Zealand, culminating in its express recognition in s 4(2)(b) of the Coroners Act 2006. This provision allows coroners to make recommendations to reduce the likelihood of deaths in similar circumstances. Recommendations are the principal mechanism by which coroners can address death and injury prevention. ${ }^{30}$ By attempting to persuade government agencies and other organisations to implement changes designed to protect the community, the coroner's focus "transcends the criminal and broadly embraces the prophylactic". ${ }^{31}$ Coroners can therefore be reasonably regarded as part of the State's public health apparatus. ${ }^{32}$

\section{Current Implementation of Recommendations}

\section{A Power to Enforce Recommendations and Factors Influencing Implementation}

In New Zealand, individuals, organisations or agencies to whom coronial recommendations are directed are not legally required to respond to, or implement,

\footnotetext{
26 Graeme Johnstone "Coroner's inquiries and recommendations" in Hugh Selby (ed) The Inquest Handbook (Federation Press, New South Wales, 1998) 38 at 42.

$27 \quad$ Harrison and Moller, above n 22, at 220.

28 Coroners Act 2006, s 13.

$29 \quad$ Freckelton and Ranson, above $\mathrm{n} 7$, at 719.

$30 \quad$ At 714.

$31 \quad$ Ian Freckelton "Death Investigation and the Evolving Role of the Coroner" (2008) 11 Otago LR 565 at 583.

32 Freckelton and Ranson, above n 7, at 719.
} 
proposed changes. ${ }^{33}$ As coroners have no formal powers to command attention, agencies and organisations that elect to ignore recommendations theoretically can do so with "impunity and without scrutiny". ${ }^{34}$ However, unlike other judicial officers, coroners' decisions frequently generate considerable publicity. ${ }^{35}$ Media reporting of coroners' findings forces agencies to defend themselves at the bar of public opinion ${ }^{36}$ and can be a powerful catalyst for promoting change. ${ }^{37}$ That said, media coverage is ultimately contingent on the degree of public interest in the incident. Where there is considerable delay between the death and the inquest, the "topicality" of the material can be seriously affected. ${ }^{38}$ Accordingly, while media attention can expedite the implementation of recommendations, if one accepts the importance of recommendations, then the current regime is plainly inadequate and fails to fulfil the public interest in death and injury prevention. ${ }^{39}$

Although they are regularly asserted to be the most influential element of coroners' findings, overseas research suggests that recommendations are rarely implemented. ${ }^{40}$ An Australian study completed in 2006 concluded that multiple factors affect implementation, including whether or not: ${ }^{41}$

- the recommendation is feasible;

- implementation accords with government policies and priorities;

- a proactive system for reviewing recommendations exists within the organisation to whom the recommendation is directed;

- prior coronial recommendations arising out of similar deaths are drawn to the attention of relevant authorities;

\footnotetext{
33 Lyndal Bugeja and David Ranson "Coroners' Recommendations: A Lost Opportunity" (2005) 13 JLM 173 at 174.

$34 \quad$ Halstead, above n 23, at 186.

$35 \quad$ Freckelton and Ranson, above $\mathrm{n} 7$, at 616.

$36 \quad$ Innis MacLeod "The Ombudsman" (1966) 19 Admin L Rev 93 at 94.

37 Jack Waterford "The media and inquests" in Hugh Selby (ed) The Inquest Handbook (Federation Press, New South Wales, 1998) 52 at 64.

$38 \quad$ Waterford, above $\mathrm{n} 37$, at 54.

39 Halstead, above n 23, at 186; Freckelton "Death Investigation and the Evolving Role of the Coroner", above n 31, at 581 .

$40 \quad$ Freckelton and Ranson, above n 7, at 738.

41 Law Reform Commission of Western Australia Review of Coronial Practice in Western Australia: Discussion Paper (June 2011) at 168-169.
} 
- the inquest and its recommendations attract media attention; and

- some form of public advocacy accompanies the recommendation.

In New Zealand, coroners and families have publicly expressed concern on a number of occasions that recommendations are being ignored. ${ }^{42}$ Yet in the absence of any official reporting system for coroners' decisions, accurately determining how frequently coroners make recommendations and the extent to which recommendations are implemented, is difficult. In the course of this paper, a small-scale study was undertaken in order to ascertain whether agencies and organisations were in fact failing to act upon coroners' recommendations. The methodology and findings of this study are discussed below.

\section{B Research Methodology}

100 findings from between April 2012 to January 2013, as well as 24 findings of public interest, were selected for analysis. ${ }^{43}$ Various public agencies and private organisations were contacted and asked to provide information about whether they had received and implemented the coroners' recommendations and, if not, to provide reasons why the recommendations had not been acted upon.

Except where recommendations were targeted at private organisations, information and supporting documentation was obtained under the Official Information Act 1982 (OIA). Several of the organisations contacted did not respond to requests for information, and one OIA request was rejected. ${ }^{44}$ In 13 cases, coroners recommended that their findings be forwarded to public health agencies, such as the Centre for Adverse Reactions Monitoring, solely for data collection purposes. As such, these

42 See generally Mike Watson "Plea not to let coroners' rulings wither" Stuff.co.nz (22 March 2013); Joanne Carroll "Official road improvement ideas get lost or ignored" The New Zealand Herald (online ed, New Zealand, 19 February 2012); Lane Nichols "Key Kahui recommendation ignored in new abuse paper" The New Zealand Herald (online ed, New Zealand, 11 October 2012); "Coronial recommendations 'die in ditch' - judge" TVNZ (13 May 2012).

$43 \quad$ See Ministry of Justice "Coronial findings of public interest" <www.justice.govt.nz>.

44 See Letter from Barry Taylor (National Manager of Operations, Police National Headquarters) to Elena Mok regarding implementation of coroners' recommendations by Police (3 September 2013). 
recommendations were not included when assessing the extent of substantive implementation.

\section{Results of Study}

In total, 154 formal recommendations were made across 79 of the cases examined. ${ }^{45}$ The nature of recommendations varied significantly across cases. Some recommendations targeted highly specific issues, such as the installation of road signage ${ }^{46}$ the removal of trees along railway tracks ${ }^{47}$ and a review of street lighting in a particular area. ${ }^{48}$ Others suggested broad-ranging education campaigns ${ }^{49}$ and legal and policy changes, including an investigation of the range of charges available in hunting accidents, ${ }^{50}$ warning labels on alcohol ${ }^{51}$ and caffeinated beverages, ${ }^{52}$ and for all district health boards (DHBs) to develop protocols for the sharing of information with family members following significant events in patient mental health care. ${ }^{53}$ Even where no formal recommendations were made, the coroner would usually make comments warning affected sections of the public to take care in similar

$45 \quad$ See Appendix One, Tables 5 and 6.

46 In the matter of an inquiry into the death of Geoffrey William Druce NZCorC Hamilton CSU2011-HAM-000568, 30 August 2012; In the matter of an inquiry into the death of Gene Robert Charles Stantiall NZCorC Hamilton CSU-2011-HAM-000624, 16 May 2012; In the matter of an inquiry into the death of Pauline Winifred Wilson NZCorC Auckland CSU-2010CCH-000477, 22 May 2012.

$47 \quad$ In the matter of an inquiry into the death of Rosalyn Sylvia Yong NZCorC Palmerston North CSU-2011-PNO-000519, 27 July 2012.

48 In the matter of an inquest into the death of Norman Bruce Thompson NZCorC Oamaru CSU2010-DUN-000210, 13 January 2012.

49 See for instance In the matter of an inquest into the death of Alexis Green, an infant NZCorC Christchurch CSU-2011-CCH-000961, 7 September 2012; In the matter of an inquiry into the death of Amanda Sharon Brunt NZCorC Hamilton CSU-2011-HAM-000244, 30 July 2012; In the matter of an inquiry into the death of Blair Calvin Edwards NZCorC Christchurch CSU2010-CCH-000609, 23 November 2012; In the matter of an inquiry into the death of Geoffrey Raymond Gill NZCorC Invercargill CSU-2011-DUN-000400, 3 August 2012. See also Appendix One, Table 8 .

50 In the matter of an inquest into the death of James Wilson Dodds NZCorC Rotorua CSU2012-ROT-000308, 18 March 2013.

51 In the matter of an inquiry into the death of Megan Anne Uren NZCorC Christchurch CSU2011-CCH-000967, 22 January 2013.

$52 \quad$ In the matter of an inquiry into the death of Natasha Marie Harris NZCorC Invercargill CSU2010-DUN-000069, 11 February 2013.

53 In the matter of an inquiry into death of $M r R$ NZCorC Palmerston North CSU-2012-PNO000151,4 January 2013. 
circumstances. ${ }^{54}$ For instance, in one case the deceased drowned while trying to rescue his grandchildren from a rip. ${ }^{55}$ Although Coroner Shortland declined to make any formal recommendations, he observed that the circumstances of the case served as a reminder to all New Zealanders to never underestimate sea conditions and to be alert to how quickly conditions can change. ${ }^{56}$

The level of input participants offered in the formulation of recommendations during the inquiry also varied considerably. Agencies and organisations sometimes offered suggestions for internal changes that they believed would help prevent the incidence of similar deaths, usually where an internal review or other investigation had already been conducted. ${ }^{57}$ Where an internal review or other investigation had resulted in recommendations, but these had not yet been fully implemented by the relevant agency or organisation, the coroner would often endorse and adopt these proposals when making recommendations. ${ }^{58}$ Recommendations were also occasionally suggested by experts assisting the coroner, or by family members of the deceased, either personally or through counsel. ${ }^{59}$

Altogether, $57.14 \%$ of recommendations had been substantively implemented by the relevant agency or organisation, and $16.88 \%$ had either been partially implemented or were scheduled for further consultation. ${ }^{60}$ Most agencies gave some consideration to recommendations and offered a response. Recommendations to the Department of Corrections and the Ministries of Health and Social Development, particularly in cases involving sudden unexpected death in infancy (SUDI) or sudden infant death syndrome (SIDS), had a high rate of substantive implementation or support. ${ }^{61}$ Similarly, recommendations aimed at more limited changes, such as signage alterations or the development of specific protocols, were often quickly implemented

\footnotetext{
$54 \quad$ See Appendix One, Table 5.

55 In the matter of an inquiry into the death of Jack Maynard Wiki NZCorC Whangarei CSU2009-WHG-000270, 12 February 2013.

56 At $[40]$.

$57 \quad$ See Appendix One, Tables 9 and 10.

$58 \quad$ See Appendix One, Table 9.

$59 \quad$ See Appendix One, Table 9.

$60 \quad$ See Appendix One, Table 7.

61 See Appendix One, Chart 2.
} 
following the coroner's inquiry. ${ }^{62}$ Recommendations relating to public education also received high levels of support, generally because agencies already had campaigns in place prior to the coroner's inquiry. ${ }^{63}$ In contrast, recommendations that related to wide-ranging regulatory or legal changes tended to receive standardised responses, with little or no prospect of implementation. ${ }^{64}$ It was evident from a number of responses that some recommendations could not feasibly be implemented, even though the intention behind the recommendation may have been supported.

In several cases, implementation had not occurred because the coroner's recommendations had not been communicated to the proper agency or organisation or had been lost in the bureaucratic process. ${ }^{65}$ Alternatively, the recommendations had been forwarded to an agency with no power to make the suggested changes. For instance, the Minister of Consumer Affairs had no ability to set up a licensing regime to regulate the hire of stud and bolt guns, as recommended by Coroner Smith following the William McLay inquiry. ${ }^{66}$ These issues are unsurprising for several reasons. Firstly, agencies have different processes in place for the recording and distribution of coroners' findings and recommendations where they have been an 'interested party' in the inquiry. Secondly, there is no specific referral process for coroners' recommendations: it is up to each individual coroner to decide who to target and where to send the recommendations. ${ }^{67}$ In the course of the study, this meant that it was sometimes unclear which agency or organisation was the subject of the coroner's recommendations, particularly in transport-related deaths. ${ }^{68}$ Further, although a list is

62 See Appendix One, Chart 1.

63 See Appendix One, Chart 1.

64 See Appendix One, Chart 1.

$65 \quad$ See Appendix One, Table 7.

66 Letter from Simon Bridges (Former Minister of Consumer Affairs) to Ian Smith (Wellington Regional Coroner) regarding the Coroner's recommendations following the death of William Stuart Dalzel McLay (2 August 2012) (Obtained under Official Information Act 1982 Request to Ministry of Business, Innovation and Employment).

67 Letter from Dean Skachill (Business Services Manager of Specialist Courts, Ministry of Justice) to Elena Mok regarding referral processes in place for notifying interested parties about coroners' recommendations (31 July 2013) at 1.

68 See for instance In the matter of an inquiry into the death of Amanda Sharon Brunt NZCorC Hamilton CSU-2011-HAM-000244, 30 July 2012; In the matter of an inquiry into the death of Geoffrey William Druce, above n 46; In the matter of an inquiry into the death of Ashley Bruce Foley NZCorC Hamilton CSU-2012-HAM-000319, 23 January 2013; In the matter of an inquiry into the death of Shaun Karl Malthus NZCorC Hamilton CSU-2011-HAM-000321, 30 April 2012; In the matter of an inquiry into the death of Richard Warren Toneycliffe 
maintained by Coronial Services which states that certain agencies are to receive specific types of recommendations, whether or not a recommendation has been responded to, let alone received, by the agency or organisation in question is not followed up on by Coronial Services. ${ }^{69}$

Overall, each of the factors identified in the Australian study appear to have had an influence on the implementation of the recommendations examined as part of this paper. Despite claims that recommendations are being ignored, the results of the study suggest that most recommendations will receive at least some consideration from the relevant agency or organisation. This accords with the preliminary findings of a more comprehensive University of Otago study currently being undertaken with New Zealand Law Foundation funding. ${ }^{70}$ Nevertheless, improvements could be made to the coronial process to ensure that recommendations are consistently and effectively contributing to positive health and safety outcomes. The following Part assesses the validity of some of the criticisms levelled at recommendations in greater depth in order to determine whether modifications to the coroner's recommendation-making power are warranted.

\section{Issues Surrounding Coroners' Recommendations}

\section{A Impractical and Overly Broad Recommendations}

\section{$1 \quad$ Costly and impractical recommendations}

Recommendations can be profoundly important in highlighting dangerous practices, policies and products for government agencies, manufacturers, corporations and industrial entities, but they can also be expensive and problematic to implement. ${ }^{71}$

NZCorC Palmerston North CSU-2012-PNO-000209, 7 March 2013. In all of these cases, recommendations were simply directed to the "relevant roading authority".

69 Letter from Dean Skachill to Elena Mok, above n 67, at 1.

70 See Georgina Stylianou "Research into coroners' recommendations" Stuff.co.nz (15 May 2012); University of Otago "Otago law researchers suggest changes to improve Coroners' recommendations" (media statement, 5 August 2013). A final report outlining the study's full findings is scheduled for release in 2014.

71 Ian Freckelton "Inquest Law" in Hugh Selby (ed) The Inquest Handbook (Federation Press, New South Wales, 1998) 1 at 7. 
These recommendations are therefore less likely to receive consideration and be implemented by the relevant agency. ${ }^{72}$

In one case, the deceased, Debbie Marie Ashton, died from injuries received in a motor vehicle crash caused by another driver, Mr Barclay, who was intoxicated and driving while disqualified. ${ }^{73}$ One of the key issues at the inquest was how Mr Barclay had come to be driving a car on a public road when he had been disqualified from driving several weeks earlier. ${ }^{74}$ Coroner Evans ultimately recommended that the Ministry of Transport (MOT) consider amending the Land Transport Act 1998 to clarify that, in cases where a person is sentenced to a term of imprisonment and disqualified from driving, the disqualification order should not take effect until the date on which the person is released from prison, unless the Court decides otherwise. ${ }^{75}$

Officials later raised a number of operational and policy concerns with the Coroner's recommendations. ${ }^{76}$ For one, implementing the recommendation would have required a system for the transfer of information from the Department of Corrections to the New Zealand Transport Agency concerning release dates for prisoners with driving disqualifications. ${ }^{77}$ The cost of creating such a system (not including maintenance costs) was estimated to be in the region of $\$ 300,000$ to $\$ 400,000 .{ }^{78}$ Secondly, developing such a system was largely unnecessary: although disqualification orders usually commence from the date of sentencing, ${ }^{79}$ judges already had sufficiently wide discretion to give effect to the Coroner's concern in appropriate cases by simply ordering a term of disqualification for longer than the term of imprisonment

\footnotetext{
$72 \quad$ See Appendix One, Chart 1.

73 In the matter of an inquest into the death of Debbie Marie Ashton NZCorC Wellington CSU2006-WGN-000000, 19 December 2012.

74 At [12].

$75 \quad$ At $[55]$.

76 Dawn Kerrison and Leo S Mortimer Response to Coroner's Recommendation in Relation to the Death of Debbie Marie Ashton (Ministry of Transport, Briefing Paper OC01467, 5 April 2013) at [6] (Obtained under Official Information Act 1982 Request to the Ministry of Transport).

77 At [31].

78 At [35].

79 At [14].
} 
imposed. ${ }^{80}$ As noted in the MOT's response to the Coroner, this practice had in fact been applied in around $60 \%$ of cases in which an offender had received both a prison sentence and a disqualification. ${ }^{81}$ Finally, as demonstrated by the circumstances of the Ashton case, a driving disqualification does not actually prevent individuals from driving illegally. Accordingly, adopting the Coroner's recommendation would not necessarily have improved public safety outcomes in any meaningful way. ${ }^{82}$

Impractical and costly recommendations not only diminish public confidence in the coronial system and subject coroners to accusations of "amateur do-goodism", but also detract from the force of well-founded recommendations. ${ }^{83}$ For instance, a number of recommendations were made following an inquest into the death of Stephen Fitzgerald, who was struck by a truck while cycling. ${ }^{84}$ One of the Coroner's recommendations to the MOT - that all cyclists be required to wear high-visibility clothing while cycling on public roads - was met with considerable opposition from

officials, cycling groups and the public, ${ }^{85}$ despite the Coroner's comments that such a move was "common sense" and a "no-brainer". ${ }^{86}$ The media made much of the fact that the deceased had been wearing reflective stripes and had his front and rear lights working at the time of the accident. ${ }^{87}$ The MOT consequently declined to adopt the recommendation on the basis that legal regulation or increased enforcement in this

\footnotetext{
$80 \quad$ At [37].

81 At [7].

82 Letter from Gerry Brownlee (Minister of Transport) to Garry Evans (Coroner for Wellington region) regarding recommendations made following Debbie Marie Ashton inquest (11 April 2013) at 3 (Obtained under Official Information Act 1982 Request to Ministry of Transport). Freckelton and Ranson, above n 7, at 737-738. See further David Farrar "Coroner recommendations" (18 February 2013) Kiwiblog <www.kiwiblog.co.nz>; David Farrar Another daft Coroner recommendation (15 February 2013) Kiwiblog <www.kiwiblog.co.nz $>$. In the matter of an inquest into the death of Stephen Fitzgerald NZCorC Wellington CSU2008-WGN-000310, 31 January 2013.

85 Henry Peach and Leo S Mortimer Response to Coroner Ian Smith's Recommendations on Cycle Safety - Questions and answers to support Minister Woodhouse's response to Coroner Ian Smith (Ministry of Transport, Briefing Paper OC01501, 15 March 2012) at 1 (Obtained under Official Information Act 1982 Request to the Ministry of Transport).

$86 \quad$ At [35].

87 In the matter of an inquest into the death of Stephen Fitzgerald, above n 84, at [11]; Farrar "Coroner recommendations", above n 83; Hilleke "Another 'no brainer' Coroner's report (February 2013) Cycling in Wellington <www.cyclingwellington.co.nz>; "Cycling group opposes mandatory high-visibility clothing" (15 February 2013) Radio New Zealand News $<$ www.radionz.co.nz $>$.
} 
area was undesirable and would deter many New Zealanders from cycling. ${ }^{88}$ However, several of the Coroner's less-publicised suggestions were accepted and quickly acted upon by the local council, including a further review of the accident site "so as to provide an adequate separation between cyclists and other forms of traffic utilising that area". ${ }^{89}$

\section{Link between findings and recommendations}

Recommendations are particularly vulnerable to criticism where they appear to go beyond the circumstances of the case and evidence before the coroner. ${ }^{90} \mathrm{~A}$ recent illustration of this is the case of Natasha Harris who died from cardiac arrhythmia after consuming up to ten litres of Coke a day for many years. ${ }^{91}$ Although Coroner Crerar noted that many ingredients of Coke could be labelled as addictive, he concluded that the Coca Cola Company could not be held responsible for the health of consumers who ingested unhealthy quantities of the product. ${ }^{92}$ Yet in light of the evidence given at the inquest hearing, it was recommended that Coca Cola and the Ministry of Health consider whether warning labels should be placed on soft drinks so as to inform consumers of the health risks associated with consuming excessive quantities of such products. ${ }^{93}$ This suggestion was met with criticism from both the public and industry specialists, with New Zealand Food \& Grocery Council Chief Executive Katherine Rich stating that, "there isn't a labelling regime in the world that could have prevented the death of someone who chose to drink Coke in such large quantities". ${ }^{94}$

88 Peach and Mortimer Response to Coroner Ian Smith's Recommendations on Cycle Safety Questions and answers to support Minister Woodhouse's response to Coroner Ian Smith, above $\mathrm{n}$ 85. The Ministry supported the intent of the recommendation but preferred public education to legal regulation or increased enforcement.

Letter from Tony Stallinger (Chief Executive of Hutt City Council) to Catherine Langman (Coronial Services Unit) regarding the Coroner's recommendation to Hutt City Council following the death of Stephen Fitzgerald (25 February 2013) (Obtained under Official Information Act 1982 Request to Hutt City Council). Work on the relevant interchange is scheduled for the end of 2013.

90 Cabinet paper "Coroners Act Review: Proposals for Reform - Paper 1", above n 5, at [20.1].

$91 \quad$ An inquiry into the death of Natasha Marie Harris, above n 52.

$92 \quad$ At $[71]$.

93 At [85]-[88].

$94 \quad$ Nick Perry "2-gallon a day cola habit linked to woman's death" NBC News (online ed, New York City, 13 February 2013); Andres Jauregui "Soft Drink Warning Labels Face Criticism 
Similar recommendations were made in the case of Megan Anne Uren, who died of an acute subdural haemorrhage after a fall the previous day. ${ }^{95}$ The Coroner concluded that the death was attributable to the amount of alcohol consumed by the deceased and subsequently recommended that every container holding alcohol should be labelled with an explicit warning that excessive consumption of alcohol may be fatal. ${ }^{96}$ Although the Coroner was fairly of the view that "makers of products containing an inherently dangerous substance have an ethical obligation to warn consumers of its dangers", there was no evidence indicating that warning labels would have prevented the death in question, especially given the deceased had been diagnosed with alcoholism prior to her death. ${ }^{97}$ While it is plausible that the deceased may not have developed alcoholism had she been informed of the dangers of excessive alcohol consumption, no explanation of this kind was offered in the Coroner's finding.

Despite this, there is also evidence of coroners exercising restraint and confining their inquiries to the circumstances of the particular death in question. In an inquest into the death of Jason Clint Martin Palmer, the deceased was a Corrections Officer working at the Springhill Corrections Facility when he was punched in the head by a prisoner and killed after striking his head on the concrete walkway. ${ }^{98}$ In exploring the possible systemic failures contributing to the death, Coroner Matenga emphasised that: ${ }^{99}$

The circumstances of this case must be kept in mind and it is not in my view, an appropriate case to make such wide ranging recommendations on the housing and management of reclassified prisoners into specific units.

In another case, the Coroner determined that the deceased had died of a cardiac arrhythmia after being detained by police to provide an evidential breath test. ${ }^{100}$ At the

After Coroner's Finding On Natasha Harris' Coca-Cola Habit" Huffington Post (online ed, New York City, 19 February 2013). See also David Farrar "Coroner recommendations", above $\mathrm{n} 83$.

95 In the matter of an inquiry into the death of Megan Anne Uren, above $\mathrm{n} 51$.

96 At 2 .

$97 \quad$ At 2

98 In the matter of an inquest into the death of Jason Clint Martin Palmer NZCorC Auckland CSU-2010-AUK-000619, 22 August 2012 at [1].

$99 \quad$ At [26].

100 In the matter of an inquiry into the death of Elizabeth Jill Gilbertson NZCorC Hamilton CSU2012-HAM-000275, 27 March 2013 at [21]. 
inquest hearing, the Clinical Director of the New Zealand Forensic Pathology Service and the deceased's brother suggested several improvements that the Police could make to prevent similar deaths in the future, including carrying an emergency defibrillator and making use of CCTV on traffic alcohol buses. ${ }^{101}$ Although the Coroner considered that these suggestions were sensible and commended them to the Police as worthy of consideration, he noted that it was inappropriate to make any formal recommendations in the context of this case. ${ }^{102}$ While the use of CCTV would be helpful to the Police and the public in such inquiries, it would not have done anything to prevent deaths in similar circumstances in the future. Likewise, there was no evidence before the Court to indicate that earlier use of a defibrillator would have made any difference in this case.

\section{More than one accepted practice}

Recommendations are also likely to be misguided in circumstances where there is more than one accepted industry practice. For instance, in particular areas of medical practice, there may be genuine and ongoing disagreement as to methods of best practice, and individual doctors will often differ as to the ideal or even acceptable practice in some cases. ${ }^{103}$ Submitters to the MOJ review also raised doubts about the choice of expert witnesses used by coroners and the approach undertaken by coroners to ensure that recognised industry experts are consulted. ${ }^{104}$

If coroners only obtain advice from one practitioner at inquests, this is unlikely to address disparities of medical opinion and coroners may remain oblivious to differences of opinion within that field. ${ }^{105}$ Practitioners who hold an accepted alternative view may consequently regard any recommendations with disdain. ${ }^{106}$ For instance, an inquest into the death of Adam Barlow, an infant, determined that he had died of intrapartum asphyxia after the mother's lead maternity carer failed to

\footnotetext{
$101 \quad$ At $[18]$ and $[20]$.

102 At [21].

103 Freckelton and Ranson, above n 7, at 738.

104 Cabinet paper "Coroners Act Review: Proposals for Reform - Paper 1", above n 5, at [20.4].

$105 \quad$ Freckelton and Ranson, above n 7, at 738.

106 At 738.
} 
communicate any urgency to the hospital midwives regarding the labour. ${ }^{107}$ The New Zealand College of Midwives expressed concern about a number of Coroner Matenga's recommendations regarding the regulation of midwifery services and emphasised that there was a lack of consensus between maternity hospital policies around the world. ${ }^{108}$

\section{B Implicit Apportionment of Blame}

The inquisitorial nature of coroners' inquiries means that ordinary procedural and evidential rules devised to promote fairness to parties and witnesses ${ }^{109}$ are "eschewed in favour of a system which allows a coroner to endeavour...to discover the truth". ${ }^{110}$ Section 79(1) of the Coroners Act thus permits the coroner to admit any evidence the coroner thinks fit for the purposes of an inquiry, regardless of whether it would be admissible in court. The wide-ranging investigative powers granted to coroners under the Act, such as the power to summon ${ }^{111}$ and cross-examine witnesses, ${ }^{112}$ are also consistent with this inquisitorial jurisdiction. ${ }^{113}$

Although coroners are prohibited from conducting inquiries for the purpose of determining any kind of liability, ${ }^{114}$ coroners' findings may indirectly influence secondary criminal, civil and disciplinary proceedings. ${ }^{115}$ Similarly, coroners' recommendations have the potential to damage reputations, provoke strong emotions,

107 In the matter of an inquest into the death of Adam Barlow NZCorC Hamilton CSU-2010HAM-000021, 7 May 2012 at [85].

108 Office of the Chief Coroner of New Zealand Recommendations Recap - Issue 3 (Ministry of Justice, March 2013) at 17.

109 Evidence Act 2006, s 6(c).

110 Graeme Johnstone "An Avenue for Death and Injury Prevention" in Hugh Selby (ed) The Aftermath of Death (Federation Press, Sydney, 1992) 140 at 144.

$111 \quad$ Coroners Act 2006, s 117(3)(a)

112 Coroners Act 2006, s 88(b).

113 Law Reform Commission of Western Australia Review of Coronial Practice in Western Australia: Discussion Paper, above n 41, at 34.

Coroners Act 2006, s 57(1).

Freckelton and Ranson, above n 7, at 616. It should be noted that in New Zealand common law actions seeking damages for personal injury are barred under the accident compensation regime. Section 26 of the Accident Compensation Act 2001 provides that "personal injury" includes the death of a person. 
and can have considerable financial and political ramifications for those affected. ${ }^{116}$ This is because it is difficult, if not impossible, for coroners to recommend preventive measures without first concluding that the death in question was preventable. ${ }^{17}$ As such, the making of comments or recommendations in the course of a coronial inquiry, particularly in relation to individuals such as health professionals, may imply blame in a manner that is not conducive to a therapeutic, collaborative process. This is exacerbated by the fact that participants often have "fundamentally and adversarially opposed objectives". ${ }^{118}$ For instance, while families may wish to use the coronial process to hold individuals, agencies and companies to account and to facilitate secondary legal proceedings, individuals and agencies will often seek to minimise their role in the death and persuade the coroner not to make recommendations so as to avoid negative publicity after the inquiry's completion. ${ }^{119}$ This can result in legal disputes concerning issues of blame for past events instead of a focus on measures that could prevent future deaths in similar circumstances. ${ }^{120}$

The issue of implicit blame was addressed by the High Court in Berryman v SolicitorGeneral, where Mallon J noted that: ${ }^{121}$

...in identifying the cause and circumstances of the death, and making comments or recommendations so that lessons may be learnt, it is sometimes inevitable that fault is attributed to a party. This is not fault in the legal sense that legal consequences will follow - the findings at an inquest are not conclusive and may be traversed in other proceedings.

Thus, although coroners should exercise caution to avoid the implicit allocation of blame wherever possible, in circumstances where this is necessary to explain how the death occurred in the "widest sense of the events", then such a comment or finding is

\footnotetext{
116 Freckelton and Ranson, above n 7, at 616. See also Matthews v Hunter [1993] 2 NZLR 683 (HC) at 687 per Heron J.

117 Victoria Law Reform Committee Review of the Coroners Act 1985 (Parliamentary Paper No 229 of Session 2003-2006, 14 September 2006) at 383.

118 Freckelton "Inquest Law", above n 71, at 3.

$119 \quad$ At 7.

120 Victoria Law Reform Committee Review of the Coroners Act 1985, above n 117, at 382-383.

121 Berryman v Solicitor-General [2008] 2 NZLR 772 (HC) at [2].
} 
permissible. ${ }^{122}$ The coroner's role in searching for the "truth" is arguably better served by procedures with an inquisitorial focus, as a "strict application of the adversarial rules of evidence and procedures would severely curtail this role and unduly hamstring a coronial inquiry, effectively marginalising its community importance and effectiveness". ${ }^{123}$ Moreover, fairness to participants is ensured in a variety of ways.

Firstly, if the coroner proposes to make an adverse comment about a person or corporation, reasonable steps must be taken to notify that person or corporation of the proposed comment and then provide an opportunity to be heard, either personally or through counsel. ${ }^{124}$ Secondly, coroners will usually exclude evidence in practice if its probative value is outweighed by its prejudicial effect, or if it is irrelevant. ${ }^{125}$ Thirdly, coroners appear to be highly aware of the possibility that their comments and recommendations may imply blame and routinely reiterate in their findings that the purpose of inquiries is not to apportion liability. For instance, in an inquest into the deaths of the Kahui twins, Coroner Evans stressed several times throughout the finding that the Court was only concerned with findings of fact, as the twins' father, Chris Kahui, had already been tried and found not guilty of their murder. ${ }^{126}$ Lastly, the majority of coroners' recommendations tend to focus on remedying systemic problems, even where individual errors and oversights have been established on the evidence. One example of this is the Ashton case, discussed in Part IV A(1), where it was found that: ${ }^{127}$

...there were a series of mistakes made by individuals and that, more significantly, the systems, policies and practices of the Department of Corrections and Police at the material time were inadequate and contributed to the events which culminated in Ms Ashton's death.

\footnotetext{
122 In the matter of an inquest into the death of Halatau Kianamanu Naitoko NZCorC Auckland CSU-2009-AUK-000144, 23 August 2011 at [4].

123 Johnstone "An Avenue for Death and Injury Prevention", above n 110, at 145.

124 Coroners Act 2006, s 58(3).

125 Johnstone "An Avenue for Death and Injury Prevention", above n 110, at 144; Coroners Act 2006, s 79(2). This approach aligns with the key principles in ss 7 and 8 of the Evidence Act 2006, which relate to the general admissibility and exclusion of evidence.

126 In the matter of an inquest into the death of Cru Omeka Kahui, Infant NZCorC Auckland COR12/0020, 2 July 2012; In the matter of an inquest into the death of Christopher Arepa Kahui, Infant NZCorC Auckland COR12/0019, 2 July 2012 at [17], [18] and [184].

127 In the matter of an inquest into the death of Debbie Marie Ashton, above n 73, at [25] (emphasis added).
} 
Coroner Evans concluded that human error - despite being an "inevitable" occurrence

- was something that could nevertheless have been detected and resolved through "more effective supervision and processes designed to minimise the risk". ${ }^{128}$ Overall, the systemic focus adopted by coroners in their findings and recommendations affords significant protection to individuals by minimising opportunities for the implicit allocation of blame.

\section{Lack of Expertise}

One of the main criticisms of coroners' recommendations is whether it is appropriate for judicial officers with predominately fact-finding and investigative responsibilities to make far-reaching proposals for reform. ${ }^{129}$ Nowadays, coroners are expected to undertake an increasingly multi-faceted administrative role in managing the death investigation process, which is "above a skill level generally found among judicial officers". ${ }^{130}$ To fulfil their role as public health officials, coroners must also be capable of evaluating complex medical, technical and scientific evidence, so as to amalgamate divergent non-legal perspectives into sensible recommendations for reform. ${ }^{131}$ Formulating recommendations amenable to practical implementation requires skills of a kind typically found in high levels of specialist administrations, especially those of senior policy developers and research analysts. ${ }^{132}$ As has been observed by Ian Freckelton, "such a skill set is not easily found, let alone in one individual". 133

The perceived inability of coroners to cope with specialist evidence has been dealt with by jurisdictions in the United States and Canada by replacing the coronial system with medical examiner systems, led by qualified medical practitioners. ${ }^{134}$ Regardless

\footnotetext{
128 At [26].

129 Ian Freckelton "Death investigation, the coroner and therapeutic jurisprudence" (2007) 15 JLM 1 at 4.

$130 \quad$ Freckelton and Ranson, above n 7, at 718.

131 Freckelton "Death investigation, the coroner and therapeutic jurisprudence", above n 129, at 8. 132 Freckelton and Ranson, above $\mathrm{n} 7$, at 737.

133 Freckelton "Death investigation, the coroner and therapeutic jurisprudence", above n 129, at 8.

134 Michael King and others Non-Adversarial Justice (The Federation Press, Sydney, 2009) at 202. However, practices vary according to jurisdiction, and some American States and Canadian Provinces still have coroners.
} 
of whether investigations are led by medical or legal professionals, effective coordination between the "medical" and "circumstantial" investigation of deaths is more likely to be accomplished if one official has oversight over the entire process. ${ }^{135}$ It is not crucial for one official to be actively involved in the details of both kinds of investigation, but one official should be responsible for both and viewed as impartial by the public. ${ }^{136}$

It is submitted that legal professionals are more suited to overseeing the coronial process, as the coroner is required to exercise many judicial functions, and must "preside over an inquiry that will involve cross-examination of witnesses and arguments from a number of counsel representing interested parties". ${ }^{137}$ An understanding of legal principles is crucial in conducting inquiries and inquests, ${ }^{138}$ particularly where cases require in-depth analysis of the relevant legislative or regulatory framework. ${ }^{139}$ For instance, the inquest into the sinking of the $O$ Yang 70 involved consideration of issues of maritime law, including New Zealand's regulatory role as coastal state with the right to control and regulate fishing activity in the Exclusive Economic Zone and the question of enforcement of safe ship practices. ${ }^{140}$

Coroners also "set the bounds of the inquiry" and must make decisions concerning the admission of evidence. ${ }^{141}$ Knowledge of the rules of evidence is vital where there is contradictory evidence or issues concerning witness credibility. In the Natasha Harris case, Coroner Crerar had to assess a number of contradictory expert accounts in determining whether excessive Coca Cola consumption contributed to the deceased's fatal arrhythmia. ${ }^{142}$ Although coroners may admit any evidence for the purposes of

\footnotetext{
135 Brodrick Committee Report of the Committee on Death Certification and Coroners (HMSO, Cmnd 4810, 1971) at [9.54].

136 At [9.55].

137 Law Commission Coroners, above n 1, at [35].

$138 \quad$ At [36].

139 Death Certification and Investigation in England, Wales and Northern Ireland, Report of a Fundamental Review, above n 9, at 78.

140 In the matter of an inquiry into the death of Yuniarto Heru, Samsuri, Taefur NZCorC Wellington CSU-2010-CCH-000579, 6 March 2013 at [11].

$141 \quad R v$ HM Coroner for North Humberside and Scunthorpe Ex p Jamieson [1995] QB 1, [1994] 3 WLR 82 (CA) at 26C-D.

142 An inquiry into the death of Natasha Marie Harris, above n 52, at [28].
} 
the inquiry, ${ }^{143}$ "many of the common sense rules of evidence must be applied if the fact-finding process is to assume any integrity". ${ }^{144}$ For instance, in the Adam Barlow inquest, the deceased's parents applied for the exclusion of expert evidence on the basis that the expert in question "lacked independence". ${ }^{145}$ Coroner Matenga was subsequently required to consider principles underlying the admissibility of expert opinion evidence in deciding whether to allow the application. ${ }^{146}$ Overall, a higher proportion of court time is expended upon evaluating complex and conflicting expert evidence in the coroner's jurisdiction than in probably any other judicial context. ${ }^{147}$ This, along with the increasingly legalistic nature of inquests due to counsel representing parties more frequently, arguably warrants the appointment of legal rather than medical professionals to supervise the coronial process. ${ }^{148}$

\section{Lack of Consistency}

Prior to the Coroners Act 2006, the New Zealand coronial system was "patchy, unsystematic and inadequate", and the lack of centralised recording system meant that coroners often acted in isolation with little awareness of their colleagues' decisions. ${ }^{149}$ This lack of conformity in coronial practices led to inconsistent decision-making and recommendations. ${ }^{150}$

These problems were largely addressed through the creation of the role of Chief Coroner and the increased centralisation of coronial practices in 2006. However, one of the issues inherent in formulating recommendations from findings is that recommendations arise on a case-by-case basis and are inevitably influenced by problems raised by individual cases. ${ }^{151}$ Therefore, one of the key challenges coroners face is to refrain from making far-reaching recommendations where there is

\footnotetext{
143 Coroners Act 2006, s 79(1).

144 Ian Freckelton "Expert Proof in the Coroner's Jurisdiction" in Hugh Selby (ed) The Aftermath of Death (Federation Press, Sydney, 1992) 37 at 45.

145 In the matter of an inquest into the death of Adam Barlow, above n 107, at [14].

146 At [15]-[18].

$147 \quad$ Freckelton "Expert Proof in the Coroner's Jurisdiction", above n 144, at 37.

148 Law Commission Coroners, above n 1, at [35]. See also Appendix One, Table 4.

149 Law Commission Coroners, above n 1, at xi.

150 At [49].

151 Freckelton and Ranson, above n 7, at 738.
} 
insufficient evidence to support their proposals, whilst still offering solutions which have some broader social benefit. ${ }^{152}$

This task is made more difficult by the fact that there is no official law reporting system for coronial decisions. There is evidence that coroners do already refer to previous coronial decisions in identifying trends in dangerous practices and formulating recommendations. ${ }^{153}$ For instance, in a number of cases involving SUDI or SIDS, coroners have essentially reiterated principles and recommendations from previous cases ${ }^{154}$ (albeit sometimes adapting their recommendations to the particular circumstances of the case before them). ${ }^{155}$ Yet the absence of an official reporting system impedes the ability, not only of coroners, but also of lawyers and researchers to identify common themes between cases, thus making the task of prevention more difficult and time-consuming than it needs to be. ${ }^{156}$

\section{E Overlap with Other Investigating Authorities}

As discussed, the coroner's role in death prevention has become a prominent characteristic in the evolution of coronial law, both in New Zealand and in overseas jurisdictions. ${ }^{157}$ However, other agencies with recommendatory functions are also equipped to undertake such a role. ${ }^{158}$ Various authorities have statutory

$152 \quad$ Freckelton and Ranson, above $\mathrm{n} 7$, at 738.

153 Coroners referred to previous coronial decisions in $11 \%$ of the cases examined. See Appendix One, Table 2.

154 See for instance In the matter of an inquest into the death of Alexis Green, an infant, above $\mathrm{n}$ 49; In the matter of an inquest into the death of Rakaua Rawhira Rongen NZCorC Invercargill CSU-2011-DUN-000435, 7 August 2012; In the matter of an inquest into the death of Baby J NZCorC Rotorua CSU-2010-ROT-000045, 13 June 2012; In the matter of an inquest into the death of Tahi Elvis Edwards NZCorC Rotorua CSU-2011-ROT-000008, 30 August 2012; In the matter of an inquiry into the death of Mason William Roy Fraser NZCorC Dunedin CSU2011-DUN-000314, 10 December 2012; In the matter of an inquest into the death of Chesara Anna-Rose McMurdo NZCorC Invercargill CSU-2010-DUN-000348, 25 May 2012.

155 See In the matter of an inquest into the death of Alexis Green, an infant, above $\mathrm{n}$ 49, at [106]. The Coroner endorsed statements made by other coroners relating to safe sleeping education for babies, but tailored her recommendations "specifically in relation to the older baby". See also Office of the Chief Coroner of New Zealand Recommendations Recap - Issue 1 (Ministry of Justice, July 2012), which contains a specific study of this line of cases.

156 University of Otago "Otago law researchers suggest changes to improve Coroners' recommendations" (media statement, 5 August 2013).

157 Freckelton and Ranson, above n 7, at 720.

$158 \quad$ At 756. 
responsibilities to enquire into the causes and circumstances of deaths in particular cases, including the Independent Police Conduct Authority, ${ }^{159}$ the Civil Aviation Authority, 160 mortality review committees, 161 and the Transport Accident Investigation Commission. ${ }^{162}$ The Coroners Act refers to 13 such authorities, as well as Royal Commissions and Commissions of Inquiry. ${ }^{163}$ Because of the similarities between the powers and functions of coroners and other investigating authorities, in some circumstances there can be confusion as to which authority should accept jurisdiction. As well, the boundaries of the coroner's jurisdiction are not explicitly defined in the Coroners Act, which can sometimes result in unnecessary investigations being conducted.

The proliferation of such specialist authorities, and the consequent "erosion of the role and responsibilities of coroners", ${ }^{164}$ begs the question whether coroners are the best placed to be making broad-based recommendations or whether they are simply creating unnecessary bureaucracy. ${ }^{165}$ Nonetheless, it is important to remember that coroners' constitutional status is fundamentally different to that of administrative or government agencies. ${ }^{166}$ Coroners are independent judicial officers and preside over inquests involving the cross-examination of witnesses and arguments from counsel for interested parties. ${ }^{167}$ Coroners' jurisdiction is thus "judicial and wholly untrammelled", unlike other agencies whose investigations are more restricted in function and scope. ${ }^{168}$ As such, the investigating coroner, involved in all aspects of administration of cases, is able to take into account the bigger picture and is well placed to evaluate future risks. ${ }^{169}$ Furthermore, inquiries into sudden deaths or deaths in custody and care

\footnotetext{
159 Independent Police Conduct Authority Act 1988, s 4.

160 Civil Aviation Act 1990, s 72A.

161 There are currently four mortality review committees in New Zealand: The Child and Youth Mortality Review Committee, the Perinatal and Maternal Mortality Review Committee, the Family Violence Death Review Committee and the Perioperative Mortality Review Committee. All of the Committees were established under ss 11 and 18 of the New Zealand Public Health and Disability Act 2000.

162 Transport Accident Investigation Commission Act 1990, s 3.

163 Section 9, definition of "other investigating authority".

164 Law Commission Coroners, above n 1, at [95].

165 Freckelton and Ranson, above n 7, at 738.

166 Law Commission Coroners, above n 1, at [97].

167 At [35].

168 At [100]-[101].

169 Johnstone "Coroner's inquiries and recommendations", above n 26, at 42.
} 
are arguably best conducted "under the auspices of someone who is independent of the medical profession, of the police and of 'government' in its widest sense". ${ }^{170}$ This ensures public confidence in the findings of the inquiry, as internal inquiries may not be seen as entirely detached from the circumstances of the death.

\section{F 'Stale' Recommendations - Delays in Completion of Findings}

Coroners' cases involving an inquest or a hearing on the papers under s 77 take over 400 days on average to complete, and over 700 days if the inquiry has to be adjourned while waiting for another investigation to be completed. ${ }^{171}$ Even if no inquiry is necessary, cases take approximately 133 days to be closed. ${ }^{172}$ The length of time taken to complete coronial cases is influenced by a multitude of factors. The coronial process requires information to be collected from numerous sources by different officials, depending on the circumstances of the individual case. ${ }^{173}$ If a person is charged with a criminal offence relating to the death or its circumstances, and the coroner is satisfied that to proceed with an inquiry might prejudice that person, the coroner will typically adjourn the inquiry until criminal proceedings are finally concluded. ${ }^{174}$ Section $68(6)$ provides that criminal proceedings are only finally concluded if no appeal or further appeal can be made in the course of the proceedings. The mandatory requirement to hold an inquest where there has been a death in official or care under s 80 (a) has also resulted in unnecessary inquests being held where death has been the result of natural causes. ${ }^{175}$

\footnotetext{
170 Brodrick Committee Report of the Committee on Death Certification and Coroners, above $\mathrm{n}$ 135, at [9.56].

171 Cabinet paper "Coroners Act Review: Proposals for Reform - Paper 1", above n 5, at [28]. Section 69 of the Coroners Act sets out the relevant procedure to be completed if another investigation is being or is likely to be conducted. See also Appendix One, Table 1.

172 No inquiry is necessary in around $55 \%$ of cases, typically where death is found to be from natural causes.

173 Cabinet paper "Coroners Act Review: Proposals for Reform - Paper 1", above n 5, at [29].

174 Coroners Act 2006, s 68. See for example In the matter of an inquest into the death of Debbie Marie Ashton, above n 73. Criminal proceedings were brought against the other driver for manslaughter and various other offences. The coronial case was not completed until 6 years after the accident.

175 Cabinet paper "Coroners Act Review: Proposals for Reform - Paper 1", above n 5, at [57]. $58 \%$ of deaths in custody since July 2007 appeared to have been from natural causes. See for instance In the matter of an inquest into the death of Michael Lyndsay Grant NZCorC Invercargill CSU-2011-DUN-000173, 23 April 2012.
} 
Protracted delays in the completion of cases can prolong grief for families and prevent them from moving forward with their lives. ${ }^{176}$ As well, delay in the completion of findings not only postpones the benefits society derives from recommendations designed to improve public safety, but also diminishes the relevance of some coroners' recommendations and causes them to become 'stale'. ${ }^{177}$ An example of this is the case of Glenn Richard Albert Mills, who died from self-inflicted injuries at Mount Eden Men's Prison. ${ }^{178}$ Coroner Greig noted that recommendations related to matters that might prevent deaths at the prison in similar circumstances were irrelevant because the prison had closed prior to the inquest. ${ }^{179}$ Similarly, after an inquiry into the death of Jacquelin Pukeroa, Coroner Shortland declined to make any recommendations because new protocols had already been introduced to address systemic errors identified following a separate review into the death by St John Ambulance. ${ }^{180}$

Accordingly, ensuring coronial processes are efficient is not straightforward given that delays can occur at different stages and for a multitude of reasons. Coroners already have the ability to postpone or adjourn an inquiry if another investigating authority is conducting an investigation into the death, and where that investigation is likely to establish the identity of the person who has died and the cause and circumstances of death. ${ }^{181}$ Further, coroners are obliged to perform their duties without delay "so far as is consistent with justice and practicable to do so". ${ }^{182}$ However, as is addressed in Part VI, the Coroners Act could be amended to more clearly define the circumstances in which coroners have jurisdiction to hold inquiries and inquests into certain deaths.

Overall, many of the criticisms levelled at coroners' recommendations are either overstated or could be addressed through reforms to the coronial process. In

\footnotetext{
176 Cabinet paper "Coroners Act Review: Proposals for Reform - Paper 1", above n 5, at [28].

177 Cabinet paper "Coroners Act Review: Proposals for Reform - Paper 1", above n 5, at [28].

178 In the matter of an inquest into the death of Glenn Richard Albert Mills NZCorC Auckland CSU-2009-AUK-001614, 17 July 2012.

179 At [85].

180 In the matter of an inquiry into the death of Jacquelin Pukeroa NZCorC Whangarei CSU2008-WHG-000156, 10 February 2013 at [91].

$181 \quad$ Coroners Act 2006, s 69.

182 Coroners Act 2006, s 5.
} 
proposing any modifications to the coronial process, it is contended that proper consideration ought to be given to the principles of therapeutic jurisprudence.

\section{A Therapeutic Framework}

\section{A Principles of Therapeutic Jurisprudence}

Therapeutic jurisprudence was originally developed in the field of mental health law and examines the psychological impact of laws in practice. ${ }^{183}$ There are four overlapping inquiries in therapeutic jurisprudence: ${ }^{184}$

(1) the role of the law in producing psychological dysfunction;

(2) therapeutic aspects of legal rules;

(3) therapeutic aspects of legal procedures; and

(4) therapeutic aspects of judicial and legal roles.

Essentially, therapeutic jurisprudence attempts to identify how legal actors, rules and procedures can produce healing or adverse effects, and suggests that we should seek to minimise the adverse effects of laws and maximise their healing effects in undertaking legal reform. ${ }^{185}$ In doing so, it must be recognised that "law is a practice, not just formal enactments in decisions or statutes". ${ }^{186}$ Changes will occur when actors in the process alter their behaviour, not just when legislative amendments are enacted. ${ }^{187}$

The co-founders of therapeutic jurisprudence, David Wexler and Bruce Winick, describe it as a "truly interdisciplinary enterprise", a vehicle for exploring "ways in which, consistent with principles of justice, the knowledge, theories, and insights of

183 Nathalie Des Rosiers "Rights Are Not Enough: Therapeutic Jurisprudence Lessons for Law Reformers" (2002) 18 Touro L Rev 443 at 443.

184 David B Wexler Therapeutic Jurisprudence: The Law as a Therapeutic Agent (Carolina Academic Press, North Carolina, 1990) at 4.

185 David B Wexler and Bruce J Winick "Introduction" in David B Wexler and Bruce J Winick (eds) Law in a Therapeutic Key: Developments in Therapeutic Jurisprudence (Carolina Academic Press, Michigan, 1996) i at xvii.

186 Rosiers, above n 183, at 455.

187 At 455. 
the mental health and related disciplines can help shape the development of the law". ${ }^{188}$ A therapeutic perspective is important because counter-therapeutic consequences are not merely damaging to the individuals affected; they also may well inhibit the fulfilment of the purpose of the legal processes themselves, such as the promotion of justice and the preservation of relationships. ${ }^{189}$ Although it is possible to speculate about the therapeutic consequences of various legal processes, empirical research is often needed to confirm whether the law is actually operating in accordance with these assumptions. ${ }^{190}$ Additionally, the involvement of participants through consultation and qualitative studies is also crucial, as statistics removed from their context can be misleading. ${ }^{191}$

\section{B Applicability of Therapeutic Jurisprudence to the Coronial Process}

Even before the advent of therapeutic jurisprudence, contemporary approaches to the coronial system and the conduct of inquiries and inquests have long been informed by an awareness of the potential for coronial processes to have both therapeutic and counter-therapeutic consequences. ${ }^{192}$ There is a growing body of research about the adverse effects that coronial processes insensitive to the needs of families can have on the wellbeing of family members. ${ }^{193}$ A significant part of the Law Commission's review of the coronial system in 2000 addressed the concerns of Māori and other cultural and religious groups, as well as many individual families, that coronial practices were insensitive, particularly in their treatment of the deceased and in respect of the removal and retention of body parts. ${ }^{194}$ These concerns were a key focus of the 2006 reforms to the coronial process. Section 3(2)(b)(i) of the Coroners Act expressly confirms that the cultural and spiritual needs of the family and those

188 David B Wexler "An Orientation to Therapeutic Jurisprudence" (1994) 20(2) New Eng J on Crim \& Civ Confinement 259 at 259.

$189 \quad$ King and others, above n 134, at 27.

190 Wexler, "An Orientation to Therapeutic Jurisprudence", above n 188, at 260.

$191 \quad$ Rosiers, above n 183, at 454.

192 Freckelton "Death investigation, the coroner and therapeutic jurisprudence", above n 129, at 1.

193 King and others, above n 134, at 205. See generally Daniel Harwood and others "The grief experiences and needs of bereaved relatives and friends of older people dying through suicide: a descriptive and case-control study" (2002) 72 Journal of Affective Disorders 185; Lucy Biddle "Public hazards or private tragedies? An exploratory study of the effect of coroners' procedures on those bereaved by suicide" (2003) 56 Social Science \& Medicine 1003; Victoria Law Reform Committee Review of the Coroners Act 1985, above n 117. 
closely connected with the deceased must be taken into account in the conduct of coronial inquiries.

Freckelton has proposed that the coronial process is "particularly well placed to benefit from the influence of therapeutic jurisprudence". ${ }^{195}$ The investigation of deaths occurring in unnatural, surprising and ambiguous circumstances can be an extremely arduous experience for family members affected by grief and distress from an unexpected bereavement. As the coroner is responsible for managing all aspects of the investigation into the death, the manner in which the coronial process interacts with family members of the deceased, from the point the coroner is informed of a death through to the completion of an inquiry or inquest, can either exacerbate distress or facilitate closure. ${ }^{196}$ It is usually difficult, if not impossible, for judicial officers to develop any kind of interactive relationship with the parties that come before them. ${ }^{197}$ Coroners, in contrast, are able to address issues, on the family's behalf, that may prevent other members of the public from befalling a similar fate to the deceased. ${ }^{198}$ Further, coroners have the opportunity to engage in a "constructive dialogue" with the family by listening and addressing any concerns regarding the death, which is "perhaps the aspect of the jurisdiction for which families are most grateful". ${ }^{199}$

In addition, various professionals and agencies, including the police, pathologists, forensic services, medical practitioners, technical and scientific experts and government agencies, routinely participate in the coronial process. As each profession brings their own discipline-specific expertise to bear on the coroner's investigation, the coroner must employ the collaborative, coordinated and multi-disciplinary approach promoted in therapeutic jurisprudence scholarship in order to identify the cause and circumstances of deaths and efficiently ascertain methods of preventing future deaths.

The holding of an inquest also has the ability to attract therapeutic and countertherapeutic consequences. In a positive sense, inquests provide an opportunity for

195 Freckelton "Death investigation, the coroner and therapeutic jurisprudence", above n 129, at 1.

196 At 1.

197 Freckelton and Ranson, above n 7, at 728.

198 At 728.

$199 \quad$ At 728. 
family and those closely connected with the deceased to understand the cause and circumstances of death and achieve formal closure. ${ }^{200}$ On the other hand, some parties may wish to use the inquest as a means of publicly ascribing blame. Grief can sometimes result in unresolved vindictiveness towards persons or organisations thought to have played a part in the death, whether or not the evidence supports such beliefs. Thus, "while the location of fault may be satisfying, cleansing and vindicating for one party, it may be catastrophic for another". 201

As well, inquests will often involve a "psychological profiling" of the deceased, particularly when the coroner must determine whether the death was deliberately selfinflicted. ${ }^{202}$ Before a conclusion of suicide can be reached, there must be cogent evidence that indicates no reasonable possibility of the death being anything other than self-inflicted. ${ }^{203}$ This requirement inevitably involves a detailed assessment of the deceased's mental state prior to death, as well as scrutiny of medical records and other private documents written by the deceased. ${ }^{204}$ The examination of such material, though crucial to understanding the cause of death, can cause significant ancillary distress to families. Consequently, any endeavours by coroners to "prevent trawling through personal materials and confine exploration of them with a firm directive on relevance" will help to avoid needless trauma and minimise the counter-therapeutic consequences for those close to the deceased. ${ }^{205}$

Even after the conclusion of the coroner's inquiry, the knowledge that coroners' findings and recommendations have received proper consideration from government agencies and other organisations may heighten the therapeutic potential for family members to draw some comfort from the fact that their loved one's death led to

\footnotetext{
$200 \quad$ Freckelton and Ranson, above n 7, at 534.

$201 \quad$ At 534.

202 At 535.

203 See for instance In the matter of an inquiry into the death of TC NZCorC Palmerston North CSU-2009-PNO-000260, 23 July 2012; In the matter of an inquiry into the death of Antoine Roni Dixon NZCorC Wellington CSU-2009-AUK-000201, 17 April 2013; In the matter of an inquiry into the death of Justin James Newton NZCorC Christchurch CSU-2010-CCH-000515, 4 January 2013; In the matter of an inquiry into the death of Blair Calvin Edwards NZCorC Christchurch CSU-2010-CCH-000609, 23 November 2012.

$204 \quad$ Freckelton and Ranson, above n 7, at 535.

205 At 535.
} 
change beneficial to the community. ${ }^{206}$ Coroners' findings and recommendations assist in identifying and eliminating dangerous practices, and can therefore enhance public safety and wellbeing in numerous ways. If suspicious and unexplained deaths are not effectively investigated and proper remedial action is not undertaken in response to coroners' findings and recommendations, this can give rise to unresolved concerns and needless anxiety within the community. ${ }^{207}$

It is encouraging to see that some coroners have already begun to consciously embrace a more therapeutic approach in New Zealand. At the very least, some coroners will express their condolences for the deceased's family and friends in their formal findings. ${ }^{208}$ In the case of Halatau Naitoko, who died after an accidental police shooting, Coroner Matenga emphasised that the inquest was "an opportunity to focus on constructive matters and bring comfort and solace to grieving family and friends". ${ }^{209}$ In another case, Coroner Scott declined to traverse the contents of an apparent suicide note, so as to avoid unnecessary distress to family and friends of the deceased. ${ }^{210} \mathrm{He}$ also expressed the hope that any publication of the findings be undertaken in a "responsible, low key and dignified way" for the specific purpose of helping to reduce similar deaths in the future..$^{211}$

Freckelton "Death Investigation and the Evolving Role of the Coroner", above n 31, at 583; Michael King "Non-adversarial justice and the coroner's court: A proposed therapeutic, restorative, problem-solving model" (2008) 16 JLM 442 at 462.

Freckelton "Death investigation, the coroner and therapeutic jurisprudence", above n 129, at 3. See Appendix One, Table 2.

In the matter of an inquest into the death of Halatau Kianamanu Naitoko, above n 122, at [6]. See also In the matter of an inquest into the death of Joseph James Batchelor-Smith NZCorC Invercargill CSU-2010-DUN-000346, 21 May 2012; In the matter of an inquest into the death of Chesara Anna-Rose McMurdo, above n 154. In both cases, the Coroner expressed hope that the airing of the circumstances surrounding the deaths, both related to unsafe infant sleeping arrangements, would comfort the families and that the community would learn from the risk factors identified so that other babies might live.

In the matter of an inquiry into the death of Mr M NZCorC Palmerston North CSU-2012PNO-000310, 4 December 2012 at [3]-[4]. At [24]. 


\section{Some Criticisms of Therapeutic Jurisprudence}

One of the fundamental criticisms of therapeutic jurisprudence relates to its broad and somewhat vague conception of what is "therapeutic". ${ }^{212}$ While Wexler has previously contended that it is inappropriate to strictly define what is therapeutic, preferring instead to "roam within intuitive and common sense contours of the concept", ${ }^{213}$ both Wexler and Winick have subsequently agreed with Christopher Slobogin's suggestion that 'therapeutic' should mean anything that enhances some aspect of physical or psychological wellbeing. ${ }^{214}$

Others have argued that therapeutic jurisprudence, "while often cloaked in the language of autonomy and choice", ${ }^{215}$ may cause state authorities to engage in "covert paternalism dressed up in therapeutic language". ${ }^{216}$ However, as has been stressed by Wexler and Winick, therapeutic jurisprudence does not advocate that there should be an exclusive focus on therapeutic considerations. ${ }^{217}$ To the contrary, therapeutic considerations should be considered alongside other key values, such as procedural fairness and the integrity of the fact-finding process. ${ }^{218}$ As a result, "therapeutic jurisprudence does not itself purport to resolve the value questions". ${ }^{219}$ Instead, by highlighting therapeutic values, all competing values may be brought into sharper focus, which can enrich the decision-making process. ${ }^{220}$ Even where therapeutic values are subordinated to other values in the decision making process, therapeutic

\footnotetext{
212 Michael King "Restorative Justice, Therapeutic Jurisprudence and the Rise of Emotionally Intelligent Justice" (2008) 32 MULR 1096 at 1115.

213 David B Wexler "Reflections on the scope of therapeutic jurisprudence" (1995) 1(2) Psychology, Public Policy, and Law 220 at 221; Ian Freckelton "Therapeutic Jurisprudence Misunderstood and Misrepresented: The Price and Risks of Influence" (2008) 30 T Jefferson L Rev 575 at 579.

214 Wexler and Winick "Introduction", above n 185, at xvii.

215 John Petrila "A review of Essays in Therapeutic Jurisprudence" (1993) 10 NYL Sch J Hum Rts 877 at 882 .

216 Freckelton "Therapeutic Jurisprudence Misunderstood and Misrepresented: The Price and Risks of Influence", above n 213, at 586.

217 Wexler "An Orientation to Therapeutic Jurisprudence", above n 188, at 259.

218 At 260.

219 At 260.

220 Wexler and Winick "Introduction", above n 185, at xvii; Bruce J Winick "The Jurisprudence of Therapeutic Jurisprudence" (1997) 3(1) Psychology, Public Policy, and Law 184 at 195.
} 
jurisprudence may nonetheless suggest methods of carrying out that decision more therapeutically and effectively. ${ }^{221}$

Overall, the coronial process is especially well suited to examination through the "lens" of therapeutic jurisprudence. ${ }^{222}$ Accordingly, in discussing possible reforms to the coronial process in Part VI, consideration will be given, where possible, to whether implementing these reforms would maximise the potential for pro-therapeutic consequences, while also minimising the incidence of counter-therapeutic consequences.

\section{Suggestions for Reform}

\section{A Better Guidance for Formulating Recommendations}

The wording of findings and recommendations varies considerably amongst coroners. ${ }^{223}$ As discussed in Part IV, coroners must synthesise vast quantities of material for the purpose of formulating recommendations "in a way that is amenable to practical implementation", which can make writing findings a difficult task. ${ }^{224}$ Awareness of the fact that recommendations may result in backlash and criticism from the agencies and organisations to whom they are directed, as well as the general public, has led coroners to adopt different approaches when formulating recommendations. ${ }^{225}$ While one response has been to refrain from making recommendations unless they directly relate to the circumstances and evidence before the coroner, ${ }^{226}$ another has been to make recommendations in general terms, merely encouraging agencies and organisations to give consideration to the issues highlighted in the findings. ${ }^{227}$ Recommendations that request agencies to review procedures or investigate matters further can be of "limited value", as:228

\footnotetext{
$221 \quad$ King and others, above n 134, at 28.

222 Winick "The Jurisprudence of Therapeutic Jurisprudence", above n 220, at 185.

223 Freckelton and Ranson, above n 7, at 635.

$224 \quad$ At 737.

225 At 738.

226 See for instance In the matter of an inquest into the death of Jason Clint Martin Palmer, above $\mathrm{n}$ 98; In the matter of an inquiry into the death of Elizabeth Jill Gilbertson, above n 100. 
The need for such policy review, and awareness of that need, almost certainly exist within the agency involved, whether or not the coroner makes such a general recommendation - thus, when the finding is delivered, its impact is very restricted.

Ultimately, though, the most inadvisable approach is the formulation of impractical, broad-based recommendations that are not justified on the evidence, as this serves only to undermine public confidence in the coronial system and detract from the force of more sensible proposals.

The quality and consistency of findings and recommendations could be improved by providing coroners with express guidance on how to draft and formulate findings and recommendations. In England and Wales, following the Coroners (Amendment) Rules 2008 (UK), the Ministry of Justice issued a Guidance Note advising coroners on when to make recommendations and what information to include in reports to the relevant body. ${ }^{229}$ The Note included example paragraphs, and detailed the process coroners should undertake if there is a failure to respond to recommendations. ${ }^{230}$ The Chief Coroner may already issue practice notes to help achieve consistency in coronial decision-making under s 132(1) of the Coroners Act, though this ability is rarely used. Alternatively, coroners could be required to participate in a specialised training programme as part of their ongoing training and education. ${ }^{231}$

Overall, coroners should exercise caution when proposing wide-ranging reviews or legal reforms based on limited evidence and without clearly articulating in their findings how such measures would have prevented the relevant death. ${ }^{232}$ At the same time, coroners need to adopt a pragmatic approach and should seek to obtain "sufficient information of sufficient quality to make the decision without being

Natalia Joy Hume NZCorC Christchurch CSU-2011-CCH-000973, 3 July 2012; In the matter of an inquiry into the death of Gwenyth Elaine Kingsbury NZCorC Wellington CSU-2010WGN-000399, 29 January 2013; In the matter of an inquiry into the death of Justin James Newton, above n 203. Freckelton and Ranson, above n 7, at 738.

Ministry of Justice (UK) Guidance for coroners on changes to Rule 43: Coroner reports to prevent future deaths (14 July 2008).

At [2.6]-[2.9] and [4.8].

Coroners Act 2006, s 7(b).

Cabinet paper "Coroners Act Review: Proposals for Reform - Paper 1", above n 5, at [20.2]. 
paralysed by a quest for perfection". ${ }^{233}$ Care should, however, be taken if the proposed changes have the potential to cause harm or are costly or intrusive. ${ }^{234}$

The MOJ review has proposed that the Coroners Act should be amended to ensure recommendations and comments are specific to the case and evidence before the coroner, as well as centring on factors that contributed to the particular death. ${ }^{235}$ Such an approach would be inconsistent with the approach taken in overseas jurisdictions. Coroners in England and Wales have a wide remit to make recommendations to prevent any other deaths based on the evidence heard at inquest, not just where a similar death is likely to occur in the future. ${ }^{236}$ Similarly, in Australian states such as Queensland and Victoria, coroners may make recommendations on any matter connected with the death, including recommendations relating to public health and safety or the administration of justice. ${ }^{237}$

Nevertheless, further clarifying that coroners' recommendation-making powers are confined to the facts at issue would possibly help ensure that recommendations are being formulated in a well-reasoned and consistent manner. Even though some broadbased recommendations may be sensible, coroners are more prone to criticism where they depart from the evidence before them and agencies are subsequently unlikely to implement those recommendations. Broader issues which arise on the evidence but fall outside the scope of the inquiry could still be highlighted in coroners' findings and thus brought to the attention of organisations without making a formal recommendation under s 57(3).

\section{B Increased Collaboration with Agencies, Organisations and Family Members}

Encouraging greater collaboration between various participants in the coronial process would have considerable therapeutic benefits. The importance of a collaborative, rather than a "coercive" or "paternalistic" approach, has been a key

\footnotetext{
233 Harrison and Moller, above n 22, at 222.

234 At 222.

$235 \quad$ At [27.1] and [27.2].

$236 \quad$ Coroners Rules 1984 (UK), r 43.

237 Coroners Act 2008 (Vic), s 72(2); Coroners Act 2003 (Qld), s 3(d).
} 
focus in therapeutic jurisprudence scholarship. ${ }^{238}$ As observed by Winick, people generally: ${ }^{239}$

...do not respond well when told what to do. Unless they themselves see the merit in achieving a particular goal, they often will not pursue it, or if required to do so, will comply only half-heartedly.

In contrast, involving participants in decision-making, or even just allowing them to express their own views, "brings a degree of commitment that mobilises the selfevaluative and self-reinforcing mechanisms that facilitate goal achievement". ${ }^{240}$ Studies of people's reactions to legal processes have consistently found that people regard procedures in which they are allowed to participate as fairer, irrespective of the outcome of their experience. ${ }^{241}$ Thus, the more people participate, "the fairer they view the process and the more they are able to accept what may be a disappointing outcome". ${ }^{242}$ Similarly, and perhaps more significantly, processes that enable anger and grief to be reframed into potentially constructive outcomes are more likely to minimise the counter-therapeutic, "deleterious effects of exclusion and alienation". ${ }^{243}$

Ultimately, increased collaboration with individuals, organisations and agencies affected by coroners' recommendations prior to the release of findings would enable parties to "engage in cooperative, non-adversarial dialogue", which would "reduce the likelihood of defensive behaviour" and increase the chances of recommendations being implemented. ${ }^{244}$ Further, improving the ability of family members to participate in coronial processes not only provides better opportunities for coming to terms with grief, but also may enable some relatives to "make meaning" of the event by focusing

\footnotetext{
$238 \quad$ King and others, above n 134, at 30.

239 Bruce J Winick "On Autonomy: Legal and Psychological Perspectives" (1992) 37 Vill L Rev 1705 at 1756.

$240 \quad$ At 1757.

241 Tom R Tyler "The Psychological Consequences of Judicial Procedures: Implications for Civil Commitment Hearings" (1992) 46 SMU Law Review 433 at 436 and 439.

242 Freckelton "Death investigation, the coroner and therapeutic jurisprudence", above n 129, at 6.

243 Thomas J Scheff "Community Conferences: Shame and Anger in Therapeutic Jurisprudence" (1998) 67 Rev Jur UPR 96 at 110-111; Freckelton "Death investigation, the coroner and therapeutic jurisprudence", above n 129 , at 8 .

244 King "Non-adversarial justice and the coroner's court: A proposed therapeutic, restorative, problem-solving model", above n 206, at 461.
} 
on how the death may be used as a means of preventing other needless fatalities. ${ }^{245} \mathrm{~A}$ more collaborative and inclusive process could be achieved in several ways.

\section{Provisional release of findings}

Under s 58(3) of the Coroners Act, coroners must not make an adverse comment without taking all reasonable steps to notify the relevant person, corporation or body and must give reasonable opportunity to be heard in relation to the proposed comment, either personally or by counsel. In practice, this usually involves releasing a provisional copy of the coroner's findings to the affected party. Provisional findings could similarly be released to agencies and organisations affected by any proposed recommendations prior to the conclusion of the coroner's inquiry. Although some coroners already undertake an inclusive process and involve affected parties in the formulation of recommendations, this practice is not consistent across different regions. ${ }^{246}$ Consistency could be achieved by amending the Coroners Act to expressly permit coroners to release provisional findings in appropriate cases.

This would have numerous advantages, especially for government agencies. ${ }^{247}$ Parties would be able to consider the impact of the recommendations and take appropriate steps, including briefing all staff involved and managing any media enquiries and publicity invariably following the release of the coroner's findings. ${ }^{248}$ Submissions could be prepared detailing any objections to the recommendations or improvements

Geoffrey Glassock "Coping with Grief" in Hugh Selby (ed) The Aftermath of Death (Federation Press, Sydney, 1992) 186 at 196. Of course, family members should have the right to determine their level of participation in coronial processes, if any, depending on whether or not they are summoned by the coroner as witnesses in the inquiry. instance In the matter of an inquest into the death of Troy Macfarlane Adamson NZCorC Gore CSU-2011-DUN-000072, 25 May 2012; In the matter of an inquest into the death of Adam Barlow, above n 107; In the matter of an inquest into the death of Richard John Barriball NZCorC Balclutha CSU-2010-DUN-000364, 30 April 2012. See generally Appendix, Chart X. There is also evidence of private companies adopting this approach. See for instance In the matter of an inquiry into the death of Geok Ling Phang NZCorC Wellington CSU-2009WGN-000626, 19 March 2013; In the matter of an inquiry into the death of Rebecca Louise Stockwell NZCorC Hastings CSU-2008-CCH-000165, 29 May 2012; In the matter of an inquiry into the death of Brendon Edward Walker NZCorC Christchurch CSU-2012-CCH000077, 28 January 2013; In the matter of an inquiry into the death of William Stuart Dalzel McLay NZCorC Wellington CSU-2009-WGN-000189, 23 July 2012. 
that could be made, as well as any steps already undertaken to prevent deaths in similar circumstances. Finally, creating further opportunities for collaboration may add time and cost to the completion of some cases, yet the early release of recommendations would allow agencies to better plan for this work. ${ }^{249}$ Agencies would also be able to assess the proper level of involvement for the relevant issues on a case-by-case basis. ${ }^{250}$

Giving organisations the opportunity to cultivate a positive and proactive public image provides organisations with an incentive to act promptly following the death to identify and remedy any hazards or dangers, even before the coronial inquiry has been completed. For instance, in one case, an infant, Baby Alexis, died from SUDI in an unsafe sleeping environment. ${ }^{251}$ At the time of her death, Baby Alexis was in the care of "Mrs A", who was on a Child, Youth and Family (CYF) list of approved caregivers. ${ }^{252}$ Baby Alexis was placed in Mrs A's care despite the fact Mrs A's routine review had recommended that she was best suited to providing transitional care for seven to ten-year-old girls. ${ }^{253}$ Various factors indicated that Mrs A also had a low awareness of safe sleeping practices and environments, such as the need to ensure that Baby Alexis's face would remain clear throughout the entirety of the sleep episode..$^{254}$ Just two weeks after Baby Alexis's death, the Regional Director of the Southern Region of CYF took action and circulated information amongst site managers for their social workers and caregivers about the risks of SUDI, safe sleeping arrangements and changes that needed to be made in practice. ${ }^{255}$ Although Coroner Johnson noted that these measures were only the "first step" in preventing the incidence of similar deaths, she commended the implementation of this local practice and, in particular, the speed with which it had been enforced. ${ }^{256}$

\footnotetext{
249 Cabinet paper "Coroners Act Review: Proposals for Reform - Paper 1", above n 5, at [26].

$250 \quad$ At [25].

251 In the matter of an inquest into the death of Alexis Green, an infant, above $\mathrm{n}$ 48, at [123].

252 At [28].

253 At [31].

$254 \quad$ At $[81]$.

255 At [103].

256 At [104]. See also In the matter of an inquiry into the death of Antoine Roni Dixon, above $\mathrm{n}$ 203, at [109], where the Coroner commended the Department of Corrections for the openminded way in which it approached the giving of evidence and its review of the responsibilities it owed to the deceased.
} 
Giving parties the ability to comment on recommendations in advance would also help ensure that coroners' recommendations are well informed and realistic, which in turn would increase the likelihood of recommendations being implemented. Recommendations are also more likely to be confined to the individual circumstances of the case and evidence before the coroner where there is input from organisations and agencies. Reducing the incidence of recommendations relating to wide-ranging legal and policy reforms would also help prevent families and the public from forming unrealistic expectations as to what changes can be made to prevent future deaths.

Despite these advantages, care would need to be taken to consult all appropriate parties, as "the notion of private communication with only some of those represented at the hearing is incompatible with the exercise of judicial functions and the concepts of natural justice". ${ }^{257}$ Similar concerns were raised in Matthews $v$ Hunter, where the plaintiff sought to quash the findings of a coroner who had engaged in private consultation with two witnesses during an inquest. ${ }^{258}$ Although Heron $\mathrm{J}$ did not consider that the circumstances of the case gave "such an appearance of partiality as to justify the quashing of findings", he noted that conferring with the two witnesses in the absence of the other parties had been "unwise" and should not have occurred. ${ }^{259}$ Proper consultation with all appropriate parties may be difficult to achieve before the conclusion of the inquiry when all of the evidence has not yet been heard, and also where recommendations are focused on ameliorating broader social and legal issues that may affect multiple organisations. However, the holding of pre-inquest conferences and the amendment of provisions in the Coroners Act relating to interested parties will help to identify those who may wish to comment on recommendations.

\footnotetext{
257 Law Commission Coroners, above n 1, at [181] and [191]. This was the reason a similar proposal to implement a reporting regime with a right of reply to proposed recommendations was not accepted during the Law Commission's review of the coronial process in 2000.

$258 \quad$ Matthews v Hunter [1993] 2 NZLR 683 (HC).

$259 \quad$ At 687.
} 


\section{Better notification of interested parties}

Coroners must give family representatives, immediate family and other persons or organisations with an interest in the death notice of significant matters relating to the coroner's inquiry. ${ }^{260}$ Despite this, interested parties are not always informed of inquiries that affect them, or given the chance to participate in the inquiry and assist the coroner in formulating recommendations. ${ }^{261}$ Usually the coroner is in the best position to ascertain the identity of the appropriate agencies and organisations that should be included in the inquiry, and in high profile cases involving an inquest, agencies and organisations will generally be directly involved from the outset, so it is easy to ascertain their interest. ${ }^{262}$ However, in cases where there is limited government agency involvement or where the inquiry proceeds by way of a chambers finding - a fairly common occurrence - it may be difficult to notify all appropriate parties prior to the inquiry's conclusion. ${ }^{263}$

The MOJ review has proposed strengthening s 23 of the Coroners Act to require the coroner to consider which individuals and organisations may have an interest in the death and should be notified of the inquiry or inquest so they can give evidence. ${ }^{264}$ The Coroners and Justice Act 2009 (UK) contains a definition of "interested person", which provides coroners with detailed instructions on who should be notified of the inquiry. ${ }^{265}$ Similarly, the Coroners Act 2003 (Qld) provides examples of parties who might have a sufficient interest, such as representatives of a government department or specialist advocacy groups with particular expertise on matters which the coroner may comment on in the course of the inquiry. ${ }^{266}$ Inserting a similar definition of "interested party" into the Coroners Act would provide coroners with some guidance when deciding who should be notified of the inquiry. Section 24 of the Coroners Act should also be amended to ensure that interested parties and family members

\footnotetext{
$260 \quad$ Coroners Act 2006, s 23.

261 Cabinet paper "Coroners Act Review: Proposals for Reform - Paper 1", above n 5, at [20.3].

262 Johnstone "An Avenue for Death and Injury Prevention", above n 110, at 159.

263 Inquiries may proceed by way of a chambers finding under s 77 of the Coroners Act 2006. Between 2011 and 2012, 1,280 inquiries were opened, while 288 public inquests were held. Cabinet paper "Coroners Act Review: Proposals for Reform - Paper 1", above n 5, at [27.3]. Section 47. Section 36.
} 
automatically receive a copy of the coroner's findings and recommendations following the inquiry's completion. ${ }^{267}$

\section{Pre-inquest conferences}

Coroners regularly correspond with family members prior to inquests in order to discuss procedures and any other concerns the family may wish to raise. ${ }^{268}$ There is, however, no statutory obligation to conduct a meeting with parties prior to the inquest. As with the provisional release of findings, practices are thus inconsistent across different regions, resulting in uncertainty for individuals and organisations working in more than one place and making it difficult in some circumstances to prepare for inquests. $^{269}$

The practice of holding pre-inquest conferences should receive legislative recognition, so as to render it a formal element of the coronial process and to encourage consistency. Pre-inquest conferences have become a common feature in Queensland, where they have received statutory acknowledgement, ${ }^{270}$ and are essentially an administrative procedure akin to the case management regime in the civil context, ${ }^{271}$ designed to streamline the eventual inquest hearing. ${ }^{272}$ As such, although fairly limited in scope and subject matter, pre-inquest conferences can significantly reduce delays, particularly in the case of complex inquiries. Further, holding a conference at such an early stage demonstrates to the parties that their input and participation in the process is valued, which promotes respect for coronial processes and sets a pattern for later consultation in respect to recommendations. ${ }^{273}$

\footnotetext{
267 Cabinet paper "Coroners Act Review: Proposals for Reform - Paper 1", above n 5, at [27.9].

26815 of the cases examined indicated that the coroner had corresponded with family prior to the coroner's inquiry. See Appendix One, Table 2.

269 Cabinet paper "Coroners Act Review: Proposals for Reform - Paper 1", above n 5, at [30].

270 Coroners Act 2003 (Qld), s 34. The coroner may hold a pre-inquest conference to determine the scope of the inquest, which witnesses and evidence will be required, and any other matters necessary to ensuring the orderly conduct of the inquest.

$271 \quad$ See generally High Court Rules, Part 7 Subpart 1.

$272 \quad$ Freckelton and Ranson, above $\mathrm{n} 7$, at 550.

273 King "Non-adversarial justice and the coroner's court: A proposed therapeutic, restorative, problem-solving model", above n 206, at 449.
} 
As observed by the Law Reform Commission of Western Australia, ${ }^{274}$ the Queensland provision is an especially appealing model because it permits the publication of a notice at least 28 days in advance of the conference. ${ }^{275}$ This would be useful in alerting specialist advocacy groups and community organisations with an interest in the issues raised by the case (but not necessarily on the coroner's list of interested parties) of the intention to later hold an inquest. These groups would then be sufficiently prepared to assist the coroner in formulating recommendations at the inquest. $^{276}$

The focus at pre-inquest conferences should be on a collaborative rather than an adversarial approach, so the coroner should encourage and "actively seek input from each of the parties in relation to the relevant issues". ${ }^{277}$ Similarly, if any of the parties are legally represented, the role of counsel should be to co-operate and facilitate decision-making by consensus. This role could be explicitly recognised in any statutory provisions relating to pre-inquest conferences. ${ }^{278}$ However, in some circumstances, a collaborative decision-making model may be inappropriate. For instance, if the coroner considers that the evidence does not corroborate the parties' agreed statement of certain facts, the coroner would need to raise this issue at the conference. ${ }^{279}$ If the issue cannot be resolved, the coroner may need to direct that the issue be determined at inquest so as to protect the integrity of the fact-finding process. ${ }^{280}$ Nevertheless, where the coroner does make such a decision, it should be carried out in a therapeutic manner: the coroner should acknowledge each party's viewpoint and state that it has been accorded proper deference, as well as providing reasons for the decision. ${ }^{281}$

\footnotetext{
274 Law Reform Commission of Western Australia Review of Coronial Practice in Western Australia: Discussion Paper, above n 41, at 144-145.

275 Section 34(2).

$276 \quad$ At 145.

277 King "Non-adversarial justice and the coroner's court: A proposed therapeutic, restorative, problem-solving model", above n 206, at 449.

278 Similar obligations are placed on parties in civil proceedings in the context of discovery under r 8.2 of the High Court Rules.

279 King "Non-adversarial justice and the coroner's court: A proposed therapeutic, restorative, problem-solving model", above n 206, at 448.

280 At 449.

$281 \quad$ At 449.
} 


\section{Mandatory Response Provisions}

One way to ensure that recommendations are not lost or ignored would be to make it mandatory for agencies and organisations to whom recommendations are directed to respond within a specified time. Agencies and organisations should also be required to acknowledge receipt of the coroner's recommendations. If no acknowledgement is received, then either the Coronial Services Unit or the individual coroner should be responsible for resending the recommendations and ensuring that they have been delivered.

Various jurisdictions have already introduced mandatory response provisions and the Chief Coroner has endorsed such an approach. ${ }^{282}$ In Victoria, coroners may make recommendations concerning public health and safety to any Minister, public statutory authority or entity. ${ }^{283} \mathrm{~A}$ response must be made within three months specifying a statement of action (if any) that has, is or will be taken in relation to the recommendations. ${ }^{284}$ The coroner must subsequently publish the response online. ${ }^{285}$ Similarly, in England and Wales, agencies must respond by providing details of any action that has or will be taken, or an explanation as to why no action is proposed, within 56 days. ${ }^{286}$

Failure to provide a response is not an offence in either jurisdiction, though a "name and shame" approach is employed to encourage timely replies. ${ }^{287}$ This approach has been highly effective, and many responses are provided hastily following publication

Mike Watson "Plea not to let coroners' rulings wither" Stuff.co.nz (22 March 2013); Shane Cowlishaw "Coroners' powers may be boosted" Stuff.co.nz (1 August 2012). The University of Otago study has also found that every coroner and all but two of the 79 organisations interviewed supported mandatory response provisions. See University of Otago "Otago law researchers suggest changes to improve Coroners' recommendations" (media statement, 5 August 2013).

283 Coroners Act 2008 (Vic), s 72(2).

284 Section 72(3).

285 Section 72(5).

286 Coroners (Amendment) Rules 2008 (UK), r 43A.

287 Law Reform Commission of Western Australia Review of Coronial Practice in Western Australia: Discussion Paper, above n 41, at 173-174; Alan Fletcher Coroners' Rule 43 reports (2011) 17(6) Clinical Risk 217 at 218. 
of a failure to respond. ${ }^{288}$ It is submitted that criticism through the media is the most appropriate sanction in this context. ${ }^{289}$ The media are less likely to put pressure on agencies to consider recommendations where they are under no obligation to consider recommendations in the first place, as is presently the case. Yet it is highly improbable that the media would let agencies off lightly after failing to comply with a legal duty to respond, especially government agencies.

This process would be strengthened if coroners were willing to cultivate closer ties with the media and there is "considerable scope for creative utilisation of publicity". ${ }^{290}$ For instance, the Health and Disability Commissioner (HDC), an independent ombudsman within the public health system, regularly draws attention to matters of public concern by issuing media statements. ${ }^{291}$ Notably, the HDC has the ability to recommend practice changes so as to avoid being merely an "ambulance at the bottom of the cliff". ${ }^{292}$ Any person may be requested to notify the HDC of "the steps (if any) that the person proposes to take to give effect to that recommendation". ${ }^{293}$ If no adequate and appropriate action is taken within a reasonable time, the HDC may inform the Minister of Health. ${ }^{294}$ Granting coroners similar powers seems like a logical step given coroners' emerging role in the public health context. The Chief Coroner could record any response by an organisation or individual to comments or recommendations in the register of recommendations the Chief Coroner is already obliged to maintain under s 7(i) of the Coroners Act. ${ }^{295}$

A related issue is whether it would be appropriate to subject private entities, such as private hospitals and corporations, to such a regime. As the potential risk to the community is the same, it would make sense for mandatory response provisions to

\footnotetext{
288 Law Reform Commission of Western Australia Review of Coronial Practice in Western Australia: Discussion Paper, above n 41, at 174. MacLeod, above n 36, at 94. Freckelton and Ranson, above n 7, at 743.

Ron Paterson "The Patients' Complaints System in New Zealand" (2002) 21(3) Health Affairs 70 at 75 .

At 75 .

Health and Disability Commissioner Act 1994, s 46(1).

Health and Disability Commissioner Act 1994, s 46(2)(b).

Cabinet paper "Coroners Act Review: Proposals for Reform - Paper 1", above n 5, at [27.6].
} 
bind private bodies exercising public functions. ${ }^{296}$ It is also important to remember that compelling organisations to respond to recommendations "does not compel compliance with recommendations but does mandate responsiveness in the public interest and on the public record". 297

Ultimately, enacting mandatory response provisions would be a "powerful safeguard against apathy" and would have numerous collateral benefits. ${ }^{298}$ Public feedback on the practicality of recommendations would act as a quality control mechanism by encouraging coroners to formulate workable, informed proposals and to seek specialist advice in appropriate cases. ${ }^{299}$ Agencies regularly involved in coroners' inquiries would be more likely to establish standard procedures for receiving and responding to recommendations, which would help prevent recommendations from being lost in the bureaucratic process. The extent to which recommendations are implemented could be more easily monitored, which would further consolidate the role of coroners in death prevention. ${ }^{300}$ Finally, ensuring that recommendations are at least considered "cannot be overstated as a solace to relatives faced with a death that should not have occurred, and whose pointlessness can otherwise cause extreme distress". ${ }^{301}$

\section{Restorative Justice Conferences}

Even after the conclusion of the coroner's inquiry, the holding of a restorative justice conference offers a further opportunity for parties to heal and gain closure. ${ }^{302}$ Restorative justice conferences do not presently form part of the coronial process, ${ }^{303}$

296 Law Reform Commission of Western Australia Review of Coronial Practice in Western Australia: Discussion Paper, above n 41, at 173.

297 Freckelton "Death Investigation and the Evolving Role of the Coroner", above n 31, at 583.

$298 \quad$ Fletcher, above n 282, at 217.

299 Law Reform Commission of Western Australia Review of Coronial Practice in Western Australia: Discussion Paper, above n 41, at 171.

$300 \quad$ Freckelton "Death Investigation and the Evolving Role of the Coroner", above n 31, at 583.

$301 \quad$ Freckelton and Ranson, above n 7, at 534.

302 King "Non-adversarial justice and the coroner's court: A proposed therapeutic, restorative, problem-solving model", above n 206, at 455.

303 Informal meetings occasionally occur between parties following the release of the coroner's findings. See for instance In the matter of an inquiry into the death of Gwenyth Elaine Kingsbury, above n 227, where meetings were scheduled between the deceased's family and the local DHB to discuss concerns over the deceased's care. 
as restorative justice has traditionally focused on the restoration of victims, offenders and communities within the criminal justice system. ${ }^{304}$ However, Michael King has contended that restorative justice processes are particularly applicable to coronial cases, and may fulfil the need of some family members to confront the individual, agency or organisation directly or indirectly responsible for their loved one's death, to obtain an explanation of their conduct and to gain an apology. ${ }^{305}$ Restorative justice, similarly to therapeutic jurisprudence, therefore values "processes that empower participants and thereby promote restoration". ${ }^{306}$ Indeed, therapeutic jurisprudence would regard the restoration sought by restorative justice as therapeutic.

Restorative justice conferences could also act as an accountability mechanism by providing an opportunity for families to follow up on whether recommendations made by the coroner have been implemented. In order for this process to be effective, not only must care be taken to ensure that restorative processes are structured to minimise any power imbalances (particularly where all parties are not legally represented), ${ }^{307}$ but cases must also be properly screened for suitability. ${ }^{308}$ It may, for instance, be inappropriate for a conference to be held where the relevant agency or organisation adamantly opposes the coroner's recommendations. ${ }^{309}$ The family may be left upset, angry and disillusioned with the coronial process where the coroner's recommendations have simply been ignored.

Alternatively, separate conferences could be conducted - one to address the matters specific to the deceased and their family, and another to focus on any recommendations made by the coroner relating to public health or safety. ${ }^{310}$ At the latter type of conference, organisations and community representatives with a specific interest in the issues raised by the death could be invited to discuss the coroner's

\footnotetext{
$304 \quad$ King and others, above n 134, at 39.

305 King "Non-adversarial justice and the coroner's court: A proposed therapeutic, restorative, problem-solving model", above n 206, at 454-455.

306 King "Restorative Justice, Therapeutic Jurisprudence and the Rise of Emotionally Intelligent Justice", above n 212, at 1115.

307 John Braithwaite "Restorative Justice and Therapeutic Jurisprudence" (2002) 38(2) Crim LB 244 at 248.

308 King "Non-adversarial justice and the coroner's court: A proposed therapeutic, restorative, problem-solving model", above n 206, at 455.

309 At 455.

$310 \quad$ At 457.
} 
findings and decide how best to implement any recommendations, alongside any family members who wished to attend. ${ }^{311}$ This approach would enable the coronial process to be more responsive to issues affecting specific ethnic groups and communities. For instance, following the death of a seven-day-old baby in Martinborough from SUDI, it was reported that SUDI disproportionately affects Māori families living in the Wairarapa. ${ }^{312}$ Following the conclusion of the coroner's inquiry, a restorative justice conference could have been held so that kaumātua (Māori elders) and specialist organisations, such as Plunket, Tamariki Ora Well Child Service and Whakawhetu (a national kaupapa Māori organisation dedicated to the reduction of Māori SUDI deaths) could have collaborated and developed strategies to reduce the incidence of SUDI deaths amongst Māori families in the area.

\section{E Refining the Coroner's Investigative Function}

As discussed in Part IV, there are significant delays between deaths and the completion of findings and recommendations, which can have considerable countertherapeutic consequences for families and the wider community. While the quality of investigations should not be sacrificed in the name of efficiency, the fact that coroners' inquiries often occur months or years after the death: ${ }^{313}$

...reduces the immediacy of the coronial response, allows distress and anger to fester on the part of family and community members, and takes the sting out of recommendations by coroners for change, as these can be readily dismissed as dealing belatedly with different times and different factual scenarios than those currently obtaining.

311 Restorative processes have increasingly involved stakeholders apart from the victim and the offender, including the extended family of the victim and the offender, as well as representatives or affected members of the community. See Braithwaite "Restorative Justice and Therapeutic Jurisprudence", above n 307, at 246.

312 Vomie Springford "Baby's death prompts coroner warning" Wairarapa Times-Age (online ed, Wairarapa, 23 May 2013). Concerns about Māori mortality rates have also been raised in the context of butane-related deaths and youth suicide. See generally Kurt Bayer "Govt needs to move on butane abuse - coroner" The New Zealand Herald (online ed, New Zealand, 25 July 2013); "Iwi seek to save future leaders from suicide" Radio New Zealand News (online ed, New Zealand, 28 August 2013).

313 Freckelton and Ranson, above n 7, at 749. 
Delays could be reduced by not only refining the coroner's statutory role in relation to certain kinds of deaths, but also by clarifying the coroner's relationship with other investigative authorities.

\section{Definition of "medical-related deaths"}

Part of the concerns relating to coroners' investigations of medical-related deaths discussed in Part IV could be addressed by better defining the circumstances in which such cases need to be reported to the coroner. The definition of medical-related deaths in the Coroners Act is extremely broad, ${ }^{314}$ and subsequently encompasses almost every medical-related death. ${ }^{315}$ It does not reflect cases where there is a heightened risk of death due to terminal illness, multiple chronic conditions or incidents involving emergency surgery. ${ }^{316}$ As a result of this broad definition, medical practitioners often need to contact the coroner to discuss whether the death should be reported and the coroner should take jurisdiction, thus resulting in needless delays. ${ }^{317}$

In Victoria, coroners only have jurisdiction to investigate deaths that occur during or following a medical procedure where a registered medical practitioner would not have reasonably expected the death immediately before the procedure was undertaken. ${ }^{318}$ Similarly, in Queensland a death is "health care related" for the purposes of the Coroners Act 2003 (Qld) if an independent person qualified in the area of health care would not have expected the care to cause or contribute to the death, or for the death to occur at that time. ${ }^{319}$ All the circumstances relating to the death may be examined, such as the deceased's known state of health before the health care was provided, including whether the deceased suffered from any underlying disease, condition or injury. ${ }^{320}$ Refining the definition of medical-related deaths in the Coroners Act in a similar manner would ensure that the coronial process is focussed on cases that

\footnotetext{
$314 \quad$ Sections 13(1)(c) and 13(1)(d).

315 Cabinet paper "Coroners Act Review: Proposals for Reform - Paper 1", above n 5, at [50].

316 At $[50]$.

317 At $[50]$.

318 Coroners Act 2008 (Vic), s 4(2)(b).

319 Section 10AA(2)(b).

$320 \quad$ Subsection (4).
} 
actually warrant investigation by a judicial officer. ${ }^{321}$ This would in turn help to minimise delays in the process.

\section{Removal of requirement to hold inquest in deaths in custody cases}

One of the options proposed to increase efficiency in the MOJ review is the removal of the mandatory requirement to hold an inquest where there has been a death in official custody or care. ${ }^{322}$ Requiring an inquest is time-consuming, resource-intensive and largely unnecessary where deaths appear to be from natural causes. ${ }^{323}$

A potential danger of removing this requirement is that community concerns over deaths may not be fully resolved where it is felt that cases have received less scrutiny from an independent investigative body. ${ }^{324}$ Deaths in custody and care fall within the special category of mandated inquests in almost every jurisdiction, ${ }^{325}$ primarily due to the vulnerable status of persons who are involuntarily detained by the State. ${ }^{326}$ As the State has taken on major responsibility for these people's care and wellbeing, any death that occurs while the individual is in custody may "constitute a breach of the duty of care owed by the custodians". ${ }^{327}$ As the agencies involved in death investigation are often the same agencies responsible for managing detainees, investigation by an independent body is therefore crucial in ensuring that there is no apparent or real conflict of interest in the investigation of these deaths. ${ }^{328}$

Despite these concerns, various other safeguards exist to ensure that deaths in custody and care receive proper examination. Firstly, coroners will still be required to open an inquiry into all deaths in custody and care, ${ }^{329}$ and retain the discretion to hold an

\footnotetext{
321 The MOJ has recommended that the definition of medical-related deaths should also be formulated in consultation with relevant health sector officials. See Cabinet paper "Coroners Act Review: Proposals for Reform - Paper 1", above n 5, at [83].

$322 \quad$ At [57].

323 At [57]-[58]. 58\% of the 78 deaths in custody since 2007 appear to have been from natural causes.

324 At [60].

325 Freckelton and Ranson, above n 7, at 175.

326 At 224.

327 At 224.

328 At 225.

329 Coroners Act 2006, s 60(1)(a)(ii).
} 
inquest where this is considered necessary. ${ }^{330}$ Secondly, coroners may only hold a hearing on the papers instead of an inquest where satisfied that no person from whom evidence is to be heard for the purposes of the inquiry wishes to give evidence in person. ${ }^{331}$ Finally, other independent authorities, such as the HDC 332 and the Children's Commissioner, may also investigate deaths that occur in care or custody. ${ }^{333}$ It is also standard practice for an inspector of corrections to investigate all deaths in custody irrespective of cause. ${ }^{334}$ The Chief Ombudsman subsequently reviews the investigator's report to ensure that the investigation was conducted properly and fairly. ${ }^{335}$

The Coroners Act should also be amended to include specific criteria to assist the coroner in deciding whether or not to hold an inquest for deaths in custody or care. ${ }^{336}$ For instance, coroners should be directed not to hold inquests where it is clear beyond reasonable doubt that death resulted from natural causes. ${ }^{337}$ In contrast, where there was a possible breach of the duty of care owed by the relevant custodians, or where recommendations may be appropriate to prevent similar deaths in the future, then this may warrant the holding of an inquest. ${ }^{338}$ Family members should also have the ability to request an inquest, especially given that "where someone dies in custody... an inquest can provide the family with the only opportunity they will have of

\footnotetext{
330 Cabinet paper "Coroners Act Review: Proposals for Reform - Paper 1", above n 5, at [60].

331 Coroners Act 2006, s 77(1).

$332 \quad$ Health and Disability Commissioner Act 1994, s 40.

333 Children's Commissioner Act 2003, ss 12(1)(a) and 13(1).

334 Beverley Wakem and David McGee Ombudsman Act Investigation of the Department of Corrections in relation to the Provision, Access and Availability of Prisoner Health Services (2012) at 22. Inspectors are independent from prisons and report to the Assurance Board, but are still part of the Department of Corrections. See Review of Prisoner Complaints Processes (Ministry of Justice, April 2005) at [1.4] and [1.10]. relation to the Provision, Access and Availability of Prisoner Health Services, above n 331, at 22. An Ombudsman can also choose to conduct his or her own independent investigation, though this has never been considered necessary. The MOJ review noted that criteria would be developed in consultation with various agencies, such as the Ministries of Health and Social Development and the Department of Corrections.

337 At [61.2].

338 Similar criteria were suggested in the Death Certification and Investigation in England, Wales and Northern Ireland, Report of a Fundamental Review, above n 9, at 80, in considering whether there should be a redefinition of the circumstances in which inquests should be held. However, these criteria were not implemented in the Coroners and Justice Act 2009 (UK).
} 
ascertaining what happened". ${ }^{339}$ In Ontario, where a family member's request for an inquest is refused, the coroner must provide written reasons for the refusal and the Chief Coroner may be asked to review the decision. ${ }^{340}$ Creating a similar procedure in New Zealand would align with s 63(e) of the Coroners Act, which provides that the coroner must take into account the wishes of family members in deciding whether or not to open an inquiry in the first place. ${ }^{341}$ It also ensures that decisions are being carried out in a therapeutic manner.

\section{$3 \quad$ Memoranda of understanding with other agencies}

Clarifying the circumstances where coroners should accept jurisdiction and where they should refer cases to other investigating authorities could reduce the needless duplication and confusion between coroners and other authorities discussed above. ${ }^{342}$ The Law Commission envisioned that the creation of the role of Chief Coroner would help achieve co-ordination between coroners and other investigating authorities. As a result, one of the Chief Coroner's main functions is to "help avoid unnecessary duplication and expedite investigation of deaths by liaison, and encouragement of coordination (for example, through development of protocols), with other investigating authorities". ${ }^{343}$ Enhanced co-ordination has subsequently been achieved in some areas. For instance, the HDC signed a Memorandum of Understanding with the Office of the Chief Coroner in 2009 to improve information sharing between coroners and the HDC, and to facilitate the co-ordination of investigations in the case of medical-related deaths. ${ }^{344}$ However, submitters to the MOJ review raised concerns about the coroner's role in relation to other investigating authorities, specifically mortality review committees and transport agencies. ${ }^{345}$

\footnotetext{
$339 \quad R v$ Inner South London Coroner; ex parte Williams [1999] 1 All ER 344, (1998) 162 JP 751 (CA) at 348. 
Section 7 of the Coroners Act could be amended to strengthen the requirement for the Chief Coroner to develop agreements with other investigating authorities to clarify their role in relation to coroners. ${ }^{346}$ The MOJ review also suggested modifying the Act to allow the Chief Coroner to direct that no further investigation is needed where another authority has conducted an inquiry. ${ }^{347}$ Alternatively, s 63 could be amended to state that the coroner, when deciding whether or not it is appropriate to open an inquiry, must take into account whether another authority has already conducted an investigation into the death. In making this decision, the coroner should consider whether the fundamental purposes of coronial inquiries - namely, establishing the cause and circumstances of the death and determining whether recommendations can be made to prevent future deaths - have already been satisfied in the course of another investigation. $^{348}$

\section{F Improving Transparency and Data Collection Processes}

\section{Publication of findings and recommendations}

The development of an official reporting system for findings and recommendations would increase consistency amongst coroners' decisions, as well as enhancing the transparency of the coronial process. One of the Chief Coroner's responsibilities is to maintain a public register of summaries of recommendations, which is currently done through NZLII, a non-profit database. ${ }^{349}$ However, access to these summaries is not particularly user-friendly and work is currently being undertaken to improve the register and publish full findings. ${ }^{350}$ As access to coroners' findings and recommendations is improved, it is likely that "coroners' decisions will become subject to a level of scrutiny from which their anonymity and inaccessibility thus far have protected them", which in turn may result in decisions of a higher quality. ${ }^{351}$

\footnotetext{
346 Cabinet paper "Coroners Act Review: Proposals for Reform - Paper 1", above n 5, at [42.1]. For instance, s 160 of the Corrections Act 2004 explicitly requires the Chief Executive of Corrections to develop a protocol with the Chief Ombudsman about the assistance to be provided by the Chief Executive to the Ombudsman.

347 At [42.2].

$348 \quad$ Coroners Act 2006, s 57.

349 Coroners Act 2006, s 7(i).

$350 \quad$ Neil MacLean "Coronial reform and the role of the Chief Coroner" [2012] NZLJ 207 at 209.

351 Freckelton and Ranson, above n 7, at 736.
} 
Making findings and recommendations more accessible to the public is also conducive to preventing deaths in similar circumstances and alleviating community concerns about suspicious, sudden or unexpected deaths. That said, privacy considerations must also be taken into account in determining the appropriate scope of publication, especially where family members object to publication.

Even though coroners' findings and recommendations generally become part of the public record once the coroner's inquiry is concluded, determining whether to prohibit the making public of evidence, or authorise the publication of certain particulars relating to self-inflicted deaths, is also a recognised aspect of the coroner's role. ${ }^{352}$ Stringent restrictions exist preventing the publication of any details of self-inflicted deaths without the coroner's authority or permission, other than the name, address and occupation of the deceased and the fact that the coroner has found the death to be selfinflicted. ${ }^{353}$ Coroners regularly prohibit publication of the names of witnesses, or other details likely to lead to identification, in the interests of justice, decency, public order, or personal privacy. ${ }^{354}$ Post-mortem photographs of the deceased are also routinely subject to non-publication orders, ${ }^{355}$ and the availability of other potentially sensitive coronial documents, such as pathologists' post-mortem reports, is subject to both the Privacy Act 1993 and the Official Information Act 1982. ${ }^{356}$ Notably, the Coroners Act expressly provides that any coroner's decision relating to publication may be reviewed by the High Court. ${ }^{357}$ However, any person may access certificates of coroner's findings, ${ }^{358}$ even where the coroner has prohibited the publication of evidence given during the inquiry. ${ }^{359}$

\footnotetext{
352 Coroners Act 2006, s 4(1)(e)(ii).

353 Coroners Act 2006, s 71(2).

354 Coroners Act 2006, s 74. See Appendix One, Table 3. The High Court's decision in Gravatt v Auckland Coroner's Court [2013] NZAR 345 (HC) may, however, decrease the number of non-publication orders made in relation to the names of witnesses. In that case, the High Court held that suppression could not be approached in a "broad brush way" and that coroners needed to provide clear reasons for their decision on the basis of one of the grounds in $\mathrm{s} 74$.

355 See Appendix One, Table 3.

356 Coroners Act 2006, s 29(2).

$357 \quad$ Section 75.

358 Section 28(1).

359 Section 28(2). However, though a copy of findings may be obtained, any restrictions imposed on publication under s 71 or s 74 still apply.
} 
Determining the proper scope of publication may be characterised as a competition between private and public interests, but it must also be remembered that there is a strong public interest in protecting privacy. ${ }^{360}$ The unnecessary public disclosure of inquest details can result in reputational and employment consequences for those involved in the proceeding, as well as embarrassment, distress and humiliation. Publicity can also interfere with the dignitary interests of the deceased and intensify the grief and anguish felt by family members. ${ }^{361}$ Research undertaken in the United Kingdom and Victoria has found that unwarranted intrusions into privacy can considerably exacerbate the trauma suffered by families involved in coronial matters. $^{362}$

In an inquiry into the death of an infant, Baby L, the family requested that Coroner Smith prohibit publication of the deceased's name due to the possible trauma the deceased's sibling might suffer from any such publicity. ${ }^{363}$ Although Coroner Smith noted that it was relatively rare for coroners to prohibit publication of the deceased's name, and that this power should only be exercised very sparingly, he concluded that a non-publication order was appropriate in the circumstances. ${ }^{364}$ Similarly, in the case of TC, Coroner na Nagara considered that prohibiting publication of the deceased's name, despite being an unusual step, was justified in order to protect the dignity of TC's memory and the privacy of his family and friends. ${ }^{365}$ The Coroner emphasised that the significance of the case lay, not in the identities of those involved, nor in the means by which the deceased took his life, but in raising public awareness of the fact that professional help can and should be enlisted when people speak of or attempt suicide, even when they are resistant to being helped. ${ }^{366}$

\footnotetext{
360 Stephen Penk "Thinking about Privacy" in Stephen Penk and Rosemary Tobin (eds) Privacy Law in New Zealand (Brookers Ltd, Wellington, 2010) 1 at 19. Penk and Tobin, above n 360, at 4. The authors raise the idea of privacy as an aspect of human dignity as only one possible conception of privacy. Biddle, above n 193; Victoria Law Reform Committee Review of the Coroners Act 1985, above $\mathrm{n} 117$, at 546 . In the matter of an inquiry into the death of Baby L NZCorC Wellington CSU-2008-WGN000089, 25 July 2012 at [28].

364 At [28].

365 In the matter of an inquiry into the death of TC, above n 203, at [55].

366 At [51]-[52].
} 
Nevertheless, sometimes the public interest in the circumstances of the death will outweigh privacy considerations. In one case, the deceased's family members sought permanent suppression of the deceased's name. ${ }^{367}$ Although Coroner Smith "struggled" with the application, he emphasised that permanent prohibition should only be made in "very extraordinary circumstances", a threshold which had not been met on this occasion. ${ }^{368}$ Ultimately, the Coroner concluded that it was crucial that the public be warned about issues that had emerged at inquest relating to the provision of inadequate and deficient mental health care. ${ }^{369}$

These cases demonstrate that the weight that will be attributed to privacy interests will depend on the facts of each individual case. Coroners could raise the subject of nonpublication orders at pre-inquest conferences so that family members are given the opportunity to air any reservations or concerns at an early stage. Sensitive details that emerge during the inquiry, but are unrelated to the cause and circumstances of death, could simply be omitted from the coroner's formal findings. As aforementioned, the Coroner in the case of Mr M opted not to include the details of the deceased's suicide note in his findings, so as to avoid causing unnecessary distress to the deceased's family and friends. ${ }^{370}$

Although excluding irrelevant material from findings would be relatively straightforward, a slightly more complex issue is whether the identity of the deceased should be published in any official reports. The Family Court has posted anonymised decisions on its website since 2004 in an effort to increase public understanding and confidence in Family Court proceedings. ${ }^{371}$ Similarly, in reports published by the HDC, the names of almost every person and organisation involved in the inquiry are replaced with pseudonyms. ${ }^{372}$ However, adopting such an approach for the publication of coronial findings poses two issues. First, it would make reports difficult

\footnotetext{
367 In the matter of an inquest into the death of Leigh Galvin McGuinness NZCorC Wellington CSU-2008-WGN-000754, 14 January 2013.

368 At [61].

369 At [59].

370 In the matter of an inquiry into the death of $M r M$, above $\mathrm{n} 210$, at [3]-[4].

$371 \quad$ Pauline Tapp "Privacy Issues in the Family Court" in Stephen Penk and Rosemary Tobin (eds) Privacy Law in New Zealand (Brookers Ltd, Wellington, 2010) 277 at 279.

372 Saul Holt and Ron Paterson "Medical-legal secrecy in New Zealand" (2008) 15 JLM 602 at 602 .
} 
to read, thus rendering the content somewhat less accessible. Second, wide-scale suppression is inconsistent with the "particular need" for openness in coronial inquiries. ${ }^{373}$ One could argue that the public interest is predominately served through recommendations aimed at safeguarding others in the community from similar deaths in the future, and that publishing the recommendations by themselves (as is currently done on the NZLII website) adequately fulfils this interest. Yet this overlooks the public interest in ascertaining the identity of the deceased, which forms part of the primary purpose of coroners' inquiries. ${ }^{374}$ It also removes recommendations from their factual context and thereby diminishes the transparency of coronial decision-making.

Another option would be to publish only a selection of significant findings in full online. The selective reporting of important decisions involving matters of public interest is a common technique adopted in law reporting to prevent an unlimited proliferation of decisions. ${ }^{375}$ For instance, Supreme Court and Court of Appeal decisions of public interest are routinely published via the Courts of New Zealand website. ${ }^{376}$ A handful of coronial findings deemed to be of "public interest" are in fact already available on the MOJ website, though this list has not been updated for some time. ${ }^{377}$ However, the inherent public interest in the kinds of deaths reported to the coroner, such as deaths in custody, unnatural or violent deaths and deaths without known cause, may warrant more extensive and comprehensive publication so as to properly allay public rumours, suspicion and concern. ${ }^{378}$ Full findings could be released, but information subject to non-publication orders made under ss 71 or 74 could be redacted. Although this may impede readability to some extent, it would strike an appropriate balance between the public interest in the circumstances of the death, including the identity of the deceased, and any relevant privacy interests the coroner has seen fit to protect.

\footnotetext{
373 Freckelton and Ranson, above n 7, at 605.

374 Coroners Act 2006, ss 4(2)(a) and 57(2).

375 JM Jacobstein "Some Reflections on the Control of the Publication of Appellate Court Opinions" (1975) 27 Stan L Rev 791 at 794.

376 See Courts of New Zealand "Judicial Decisions of Public Interest" $<$ www.courtsofnz.govt.nz>.

377 See Ministry of Justice "Coronial findings of public interest" <www.justice.govt.nz>. The most recent decision is dated 25 March 2013.

378 This was identified by the Brodrick Committee in 1971 as one of the public interests which should be fulfilled at inquest. See Brodrick Committee Report of the Committee on Death Certification and Coroners, above n 135, at [14.21]-[14.23].
} 


\section{National coronial information system}

National information systems for coronial data are immensely helpful to coroners' role in death and injury prevention. ${ }^{379}$ These databases allow coroners to quickly identify similar deaths and access details of investigations and findings, ${ }^{380}$ which assists in the identification of systemic or wide-ranging risk factors. ${ }^{381}$ The Case Management System (CMS), a national database for New Zealand coronial cases, was established in July 2007. ${ }^{382}$ Previously, coroners were not required to record data on their investigations in any standardised way, so data from cases opened prior to this date is not of the same quality. CMS is managed by the Coronial Services Unit, and stores information on the person who died, how they died, and any contributing factors to their death. The database is regularly audited to ensure that the data recorded is not only of high quality, but also that coronial policies and procedures align with international best practice, such as World Health Organisation classifications for causes of death and injury. Brief summaries of police reports and the coroner's provisional and final findings also form part of the database, and data is drawn from an array of documents, including pathologist reports, medical histories, witness statements and toxicology reports.

Notably, New Zealand has recently joined the National Coroners Information System (NCIS), a national database that receives and records information on deaths reported to coroners in Australia each year. ${ }^{383}$ As a result, New Zealand cases will soon become available on the NCIS site - a promising step towards a "one stop shop" for coronial cases within Australasia. ${ }^{384}$ Unlike CMS, NCIS stores the full text of certain reports, such as police, pathologist and toxicology reports. ${ }^{385}$ This allows for more comprehensive statistical analysis, as un-coded text is often a "better way of conveying the subtleties and complexities of the events leading to injuries" and death

\footnotetext{
379 Halstead, above n 23, at 206; Harrison and Moller, above n 22, at 67.

$380 \quad$ Harrison and Moller, above n 22, at 67.

381 Freckelton and Ranson, above n 7, at 829.

382 Ministry of Justice "Coronial data collection" < www.justice.govt.nz>.

383 The Shipman Inquiry: Death Certification and the Investigation of Deaths by Coroners (HMSO, Cm 5854, July 2003) at [18.29].

$384 \quad$ MacLean, above n 350, at 209.

385 National Coronial Information System "Data from coronial files" <www.ncis.org.au>.
} 
than classified data. ${ }^{386}$ This is because text-searching techniques may reveal information not covered by standard classifications. ${ }^{387}$

More frequent use of national databases such as NCIS could mean coroners would eventually be able to acquire overseas information and supplement records of New Zealand experience with international experience. ${ }^{388}$ Some coroners already refer to overseas research in their findings. For example, during the inquest into the death of Stephen Fitzgerald, the Coroner considered that international research into cycling deaths was also applicable in the New Zealand context and used this information to formulate recommendations to prevent deaths in similar circumstances. ${ }^{389}$ International access to national databases can assist in understanding global, environmental, and community hazards and therefore has the potential to influence a wide range of public health activities. ${ }^{390}$

There are, however, two main barriers to such a development. Firstly, as with the publication of coroners' findings, privacy concerns must be taken into account in developing databases with broad access. ${ }^{391}$ NCIS data is made available to coroners, government agencies and other organisations to assist in early hazard identification and research, but is not yet publicly available or even accessible to legal practitioners involved in the coronial process without the express permission of the relevant coroner. ${ }^{392}$ Individuals and groups with a legitimate interest in public health and safety may only gain access after obtaining ethics approval. ${ }^{393}$ However, the requirement for ethics approval may represent an appropriate balance between the public interest in transparency around coronial decision-making and privacy interests concerning sensitive information contained in coronial documents, provided the

\footnotetext{
386 James Harrison and Daniel Tyson "Preventing Injury" in Hugh Selby (ed) The Aftermath of Death (Federation Press, Sydney, 1992) 233 at 237.

$387 \quad$ At 237.

388 Johnstone "Coroner's inquiries and recommendations", above n 26, at 49; Halstead, above n 23 , at 206.

389 In the matter of an inquest into the death of Stephen Fitzgerald, above n 84, at [28].

$390 \quad$ Freckelton and Ranson, above n 7, at 106.

$391 \quad$ At 106.

392 National Coronial Information System "About NCIS" <www.ncis.org.au>; Freckelton and Ranson, above $\mathrm{n}$ 7, at 734.

393 National Coronial Information System "NCIS - Frequently Asked Questions" $<$ www.ncis.org.au>. Subscription fees also apply.
} 
accountability of coroners could be ensured through other measures, such as an official reporting system for coroners' findings.

The second obstacle is that coroners' use of the NCIS thus far has been limited. ${ }^{394} \mathrm{~A}$ database search should ideally be a routine part of the death investigation process, as this would allow previously undetected trends and patterns to be identified early in the investigation, thus providing information to shape the "direction, scope and focus" of the subsequent inquiry. ${ }^{395}$ As coroners rarely have experience with statistically based empirical research techniques, unless specialists are employed fulltime by coroners' offices, "it seems unlikely that the available data sets will be mined in the way that their potential would allow". ${ }^{396}$

A noteworthy initiative in the context of SUDI deaths was the development of a pilot programme between the Ministry of Health and the National Coronial Services Unit in 2008. ${ }^{397}$ The programme resulted in the creation of the role of SUDI Referral Advisors - health trained investigators who worked with the coroner's office and other agencies to improve information collection for SUDI deaths and to provide ongoing support for family and whānau who had suffered a SUDI death. ${ }^{398}$ Another key role of Referral Advisors was to raise awareness of the key modifiable risk factors of SUDI through workshops and training programmes. ${ }^{399}$ The development of similar initiatives in other types of cases would help ensure that crucial data is being collected to support preventive measures. Though such an initiative would ultimately be dependent on resourcing and funding priorities, the cost is arguably justified given the potential of this data, if used properly, to help prevent future deaths.

\footnotetext{
$394 \quad$ Freckelton and Ranson, above n 7, at 734.

$395 \quad$ Freckelton and Ranson, above n 7, at 741.

$396 \quad$ At 741.

397 Sixth Report on the Activities of the CYMRC: 1 January to 30 June 2011 (Child and Youth Mortality Review Committee, March 2012) at 13.

398 Barbara Wright "The Role of the SUDI Referral Advisor" Whakawhetu - National SUDI Prevention for Māori <www.whakawhetu.co.nz>.

399 Neil MacLean "Confessions of a Coroner" (speech to New Zealand Medical Association Practice Conference and Medical Exhibition, Rotorua, June 2013). Though feedback has been positive, the future of the programme is uncertain. See Sixth Report on the Activities of the CYMRC: 1 January to 30 June 2011, above n 397, at 13.
} 


\section{Conclusion}

The coronial process incorporates many features which enable it to draw upon the insights of therapeutic jurisprudence scholarship. One of the most significant of these features is the ability of coroners to make recommendations to agencies and organisations in order to prevent needless fatalities within the community. This role represents a "constructive and positive functioning of the law, moving outside the straightjacket of the adversary system". ${ }^{400}$ Coroners' recommendations also carry particular therapeutic potential for families who have suffered a loss that is "otherwise hard to endure and for which the legal system may otherwise provide little in terms of solace" by redirecting families' focus towards constructive matters, specifically the avoidance of other deaths in similar circumstances. ${ }^{401}$

Despite this therapeutic potential, many recommendations are not implemented because they are perceived to be too costly, impractical and uninformed. The MOJ review's proposed legislative changes, which seek to focus coroners' recommendations on the case at hand, as well as increasing opportunities for collaboration between key parties, are a positive step forward and will help ensure that coroners are making practical recommendations, soundly based in the evidence before them. Other proposed reforms aimed at reducing delays in coronial processes will also have therapeutic benefits for families of the deceased, as well as decreasing the incidence of stale recommendations.

However, in many respects the proposed changes do not go far enough in maximising the coroner's preventive role. The quality and consistency of findings and recommendations could also be effectively enhanced through extra-legislative measures, such as the development of an official reporting system and the increased use of national databases. In addition, the holding of restorative justice conferences would provide families with the chance to follow up on whether recommendations have been implemented, as well as allowing the coronial process to be more responsive to the needs of specific communities. Most significantly, the ongoing

$400 \quad$ Freckelton "Death investigation, the coroner and therapeutic jurisprudence", above n 129, at 4.

401 Freckelton and Ranson, above n 7, at 543. 
absence of any legal requirement to reply to coroners' suggestions continues to relieve those to whom recommendations are directed of the duty to be responsive. ${ }^{402}$ Where feasible recommendations are simply ignored by agencies and organisations, this has counter-therapeutic consequences for both the deceased's family and the wider community: family members might be left disillusioned and frustrated by the outcome of the process, while hazards and risks revealed by the coroner's inquiry may result in needless fatalities within the community if left unremedied. Ultimately, greater transparency and accountability is needed for the preventive and therapeutic potential of coroners' recommendations to be fully harnessed. 
VIII Appendix One - Tables and Charts Relating to Findings of Study

Table 1. Types of case by broad category

\begin{tabular}{|c|c|}
\hline Type of case & Number of cases \\
\hline Transport-related & 44 \\
\hline Alcohol or substance-related & $(15)$ \\
\hline Work-related & $(5)$ \\
\hline Self-inflicted & 16 \\
\hline Mental health issues & (9) \\
\hline Death in official custody & (6) \\
\hline Water-related & 15 \\
\hline Drowning & (4) \\
\hline Recreational/maritime accident & $(10)$ \\
\hline Alcohol-related & (1) \\
\hline SUDI/SIDS deaths & 9 \\
\hline Deaths in official care & (1) \\
\hline Adverse reaction to medical/surgical treatment & 8 \\
\hline Labour or pregnancy-related & 2 \\
\hline Alcohol or substance-related & 4 \\
\hline Care facilities deaths & 2 \\
\hline Natural causes & 4 \\
\hline Death in official custody & (2) \\
\hline Fall & 8 \\
\hline Alcohol-related & $(2)$ \\
\hline Recreational/leisure activities & (4) \\
\hline Care facilities & (1) \\
\hline Homicide or interpersonal violence & 4 \\
\hline Work-related & 3 \\
\hline Accidental shootings & 2 \\
\hline Other & 3 \\
\hline Total & 124 \\
\hline
\end{tabular}


Table 2. General data relating to 124 cases

\begin{tabular}{|c|c|}
\hline $\begin{array}{l}\text { Inquests held } \\
\text { Joint inquests }\end{array}$ & $\begin{array}{l}55 \\
(3)\end{array}$ \\
\hline $\begin{array}{l}\text { Hearings on papers (chambers findings) } \\
\text { Joint hearing }\end{array}$ & $\begin{array}{l}67 \\
(1)\end{array}$ \\
\hline Average length of findings & 11 pages \\
\hline Average length between death and release of findings & 22 months \\
\hline Provisional findings released for adverse comment & 15 cases \\
\hline Reference to previous coronial cases in findings & $11 \%$ of cases \\
\hline Pre-inquest meeting conducted & $16.36 \%$ of inquests \\
\hline Pre-inquiry communications between coroner and deceased's family & $12.1 \%$ of cases \\
\hline Expression of condolences for family/friends of deceased in findings & $48.39 \%$ of cases \\
\hline
\end{tabular}

Table 3. Number of non-publication orders made by coroners

\begin{tabular}{|l|c|}
\hline Type of order & Number \\
\hline Prohibition in respect of evidence or witness details & 22 \\
\hline Prohibition of details relating to deceased (i.e. name, place of death) & 11 \\
\hline Prohibition on release of photos of deceased & 20 \\
\hline Reporting restrictions in self-inflicted cases (i.e. manner of death) & 12 \\
\hline Total & $\mathbf{6 5}$ \\
\hline
\end{tabular}

Table 4. Legal assistance provided in 124 cases $^{*}$

\section{Type of legal assistance $\quad$ Percentage of cases}

\begin{tabular}{lc}
\hline Counsel for family & $9.68 \%$ \\
Counsel for public agency/local body (i.e. DHBs) & $13.71 \%$ \\
Counsel for private organisation or company & $6.45 \%$ \\
Counsel for individual (i.e. health practitioners) & $12.1 \%$ \\
Counsel assisting the Court & $3.23 \%$ \\
\hline
\end{tabular}

\footnotetext{
${ }^{*}$ The accuracy of this information was dependent on the relevant parties being mentioned either in the findings themselves or in a list of attendees to the inquest.
} 
Table 5. Types of recommendations made in 124 cases

\begin{tabular}{lc}
\hline Type of recommendation made & Number of cases \\
\hline No formal recommendations & 45 \\
General warning to affected sections of the public & 28 \\
Formal recommendations & 79 \\
\hline
\end{tabular}

Table 6. Type of agencies, organisations and companies subject to recommendations

\begin{tabular}{|c|c|}
\hline Type of agency/organisation & Number of recommendations \\
\hline Government agencies & $\mathbf{8 0}$ \\
Ministry of Health & $(9)$ \\
Ministry of Social Development & $(15)$ \\
Ministry of Transport & $(10)$ \\
New Zealand Transport Agency & $(7)$ \\
Maritime New Zealand & $(9)$ \\
Ministry of Business, Innovation and Employment** & $(7)$ \\
Department of Corrections & $(17)$ \\
Department of Conservation & $(1)$ \\
Ministry of Housing & $(3)$ \\
Ministry of Consumer Affairs & $(1)$ \\
Ministry for Primary Industries & $(1)$ \\
\hline Police and emergency services & $\mathbf{1 5}$ \\
\hline Care facilities & $\mathbf{7}$ \\
\hline Hospitals and DHBs & $\mathbf{1 9}$ \\
\hline Local authorities & $\mathbf{1 3}$ \\
\hline Private companies & $\mathbf{5}$ \\
\hline Other & $\mathbf{1 5}$ \\
\hline Total & $\mathbf{1 5 4}$ \\
\hline
\end{tabular}

\footnotetext{
${ }^{* *}$ Formerly the Department of Labour.
} 
Table 7. Extent of implementation of recommendations by agencies and organisations

\begin{tabular}{|l|c|}
\hline Extent of implementation & Percentage \\
\hline 'Lost'/not referred to agency/organisation & $6.49 \%$ \\
\hline No response provided by agency/organisation & $7.79 \%$ \\
\hline Not implemented (i.e. impractical/too costly/unnecessary) & $30.19 \%$ \\
\hline Partial implementation/consultation ongoing & $16.88 \%$ \\
\hline Substantive implementation & $57.14 \%$ \\
\hline Changes made prior to coroner's inquiry & $2.6 \%$ \\
\hline
\end{tabular}

Table 8. Types of formal recommendations

\begin{tabular}{|l|c|}
\hline Type of recommendation & Number \\
\hline Legal/regulatory changes & $\mathbf{2 5}$ \\
- Wide & $(21)$ \\
- Narrow & $(4)$ \\
\hline Policy/protocol changes & $\mathbf{4 1}$ \\
- Wide & $(22)$ \\
- Narrow & $(19)$ \\
\hline Educative & $\mathbf{4 0}$ \\
- Wide (i.e. public education campaigns) & $(28)$ \\
- Narrow (i.e. specific training) & $(12)$ \\
\hline Practical changes & $\mathbf{3 1}$ \\
- Wide (i.e. product changes) & $(9)$ \\
- Narrow (i.e. signage changes) & $(22)$ \\
\hline Investigation/review needed & $\mathbf{1 7}$ \\
- Wide & $(7)$ \\
- Narrow & $(10)$ \\
\hline Forwarding offindings to agencies for data collection & $\mathbf{1 3}$ \\
\hline Total & $\mathbf{1 6 7}$ \\
\hline
\end{tabular}


Table 9. Use of external recommendations and suggestions by coroners in the formulation of recommendations

\begin{tabular}{|l|c|}
\hline Source of input & Number of cases \\
\hline Adoption of recommendations from prior investigation/review & 14 \\
\hline Informed by suggestions of counsel for family & 4 \\
\hline Informed by suggestions of counsel for other participants at inquest & 2 \\
\hline Endorsement of current practice by agency/organisation & 12 \\
\hline
\end{tabular}

Table 10. Other investigations, reviews and proceedings conducted prior to or concurrently with coronial inquiry***

\begin{tabular}{|l|c|}
\hline Type of review & Number of cases \\
\hline Police investigation & 17 \\
\hline Serious Crash Unit Investigation & 9 \\
\hline Criminal proceedings & 9 \\
\hline Disciplinary proceedings & 3 \\
\hline Health and Safety in Employment investigation & 4 \\
\hline Ministerial Inquiry & 1 \\
\hline Inspector of Corrections investigation & 1 \\
\hline Independent Police Conduct Authority investigation & 1 \\
\hline Ombudsman investigation & 21 \\
\hline Children's Commissioner investigation & 12 \\
\hline Internal review by public agency/organisation/private company & 3 \\
\hline DHB investigation & 3 \\
\hline Review by local authority & $\mathbf{1 1 5}$ \\
\hline Maritime New Zealand investigation & \\
\hline Total & 9 \\
\hline
\end{tabular}

${ }^{* * *}$ In some cases, several kinds of investigation were conducted prior to or concurrently with the coroner's inquiry. 


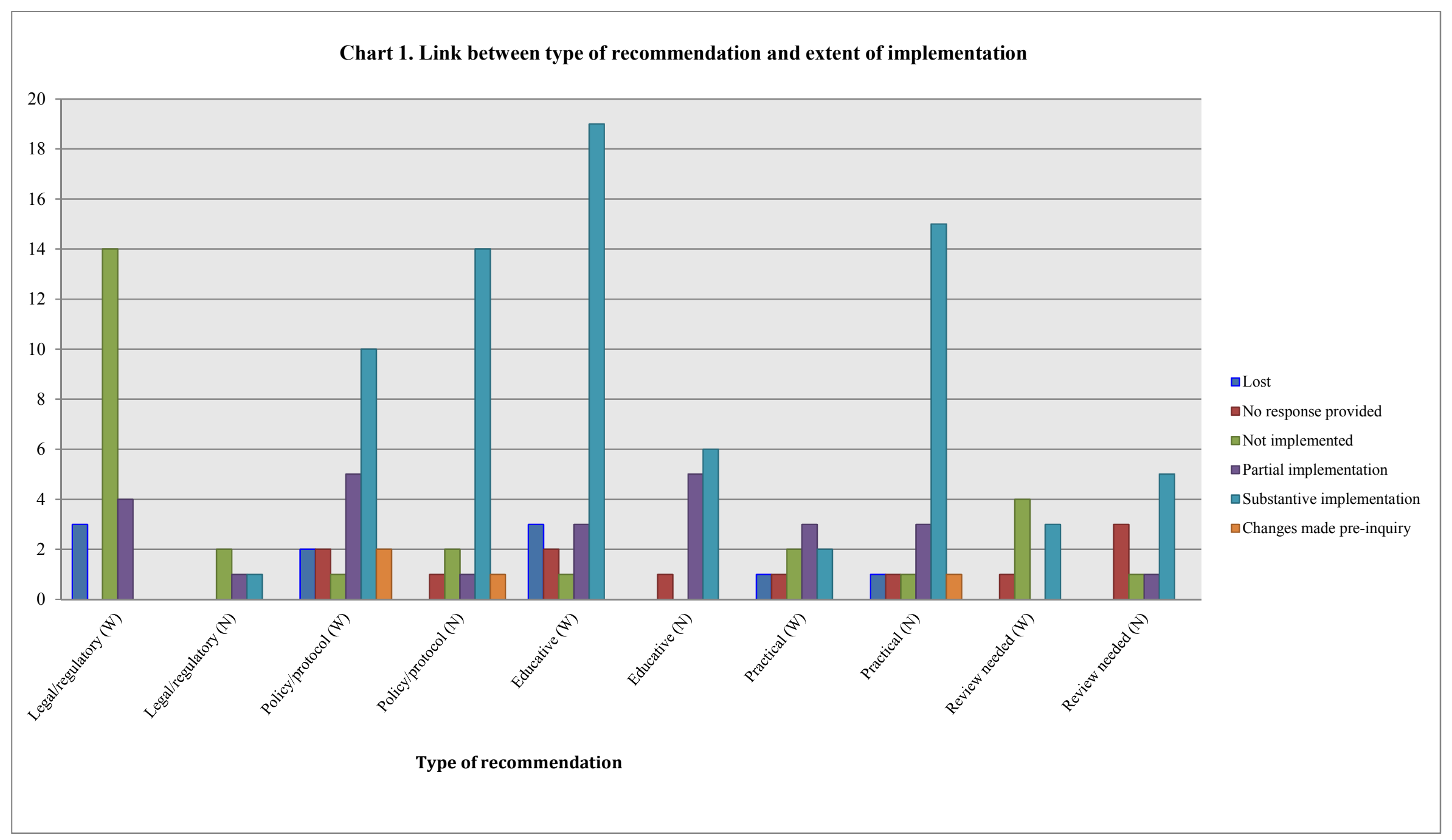

* $\mathrm{N}=$ Narrow $\quad \mathrm{W}=$ Wide 


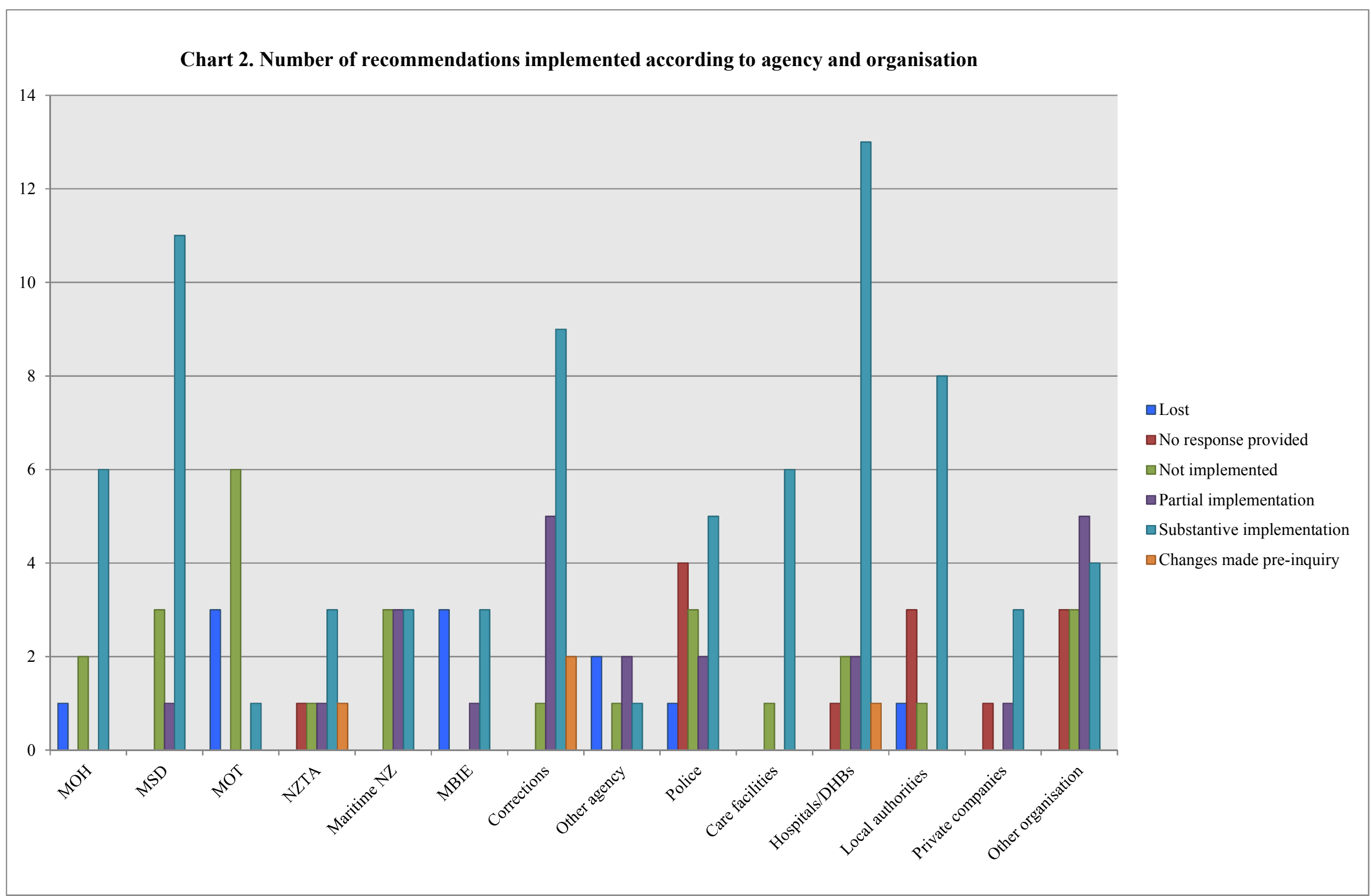




\section{Appendix Two - Flowcharts of the Coronial Process}

Diagram 1. Flowchart of the current coronial process in New Zealand

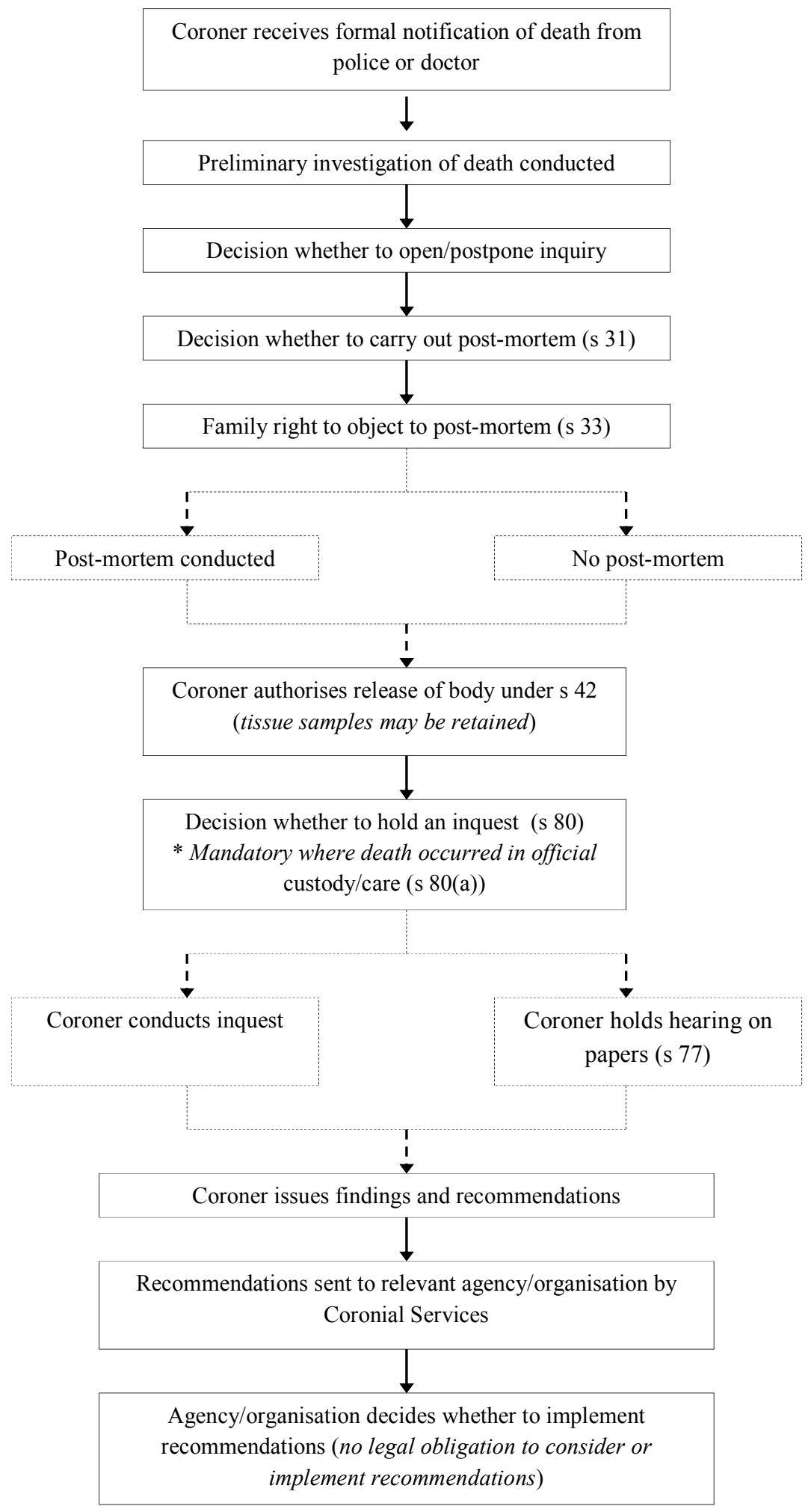


Diagram 2. Flowchart of coronial process up until release of findings with author's proposed reforms

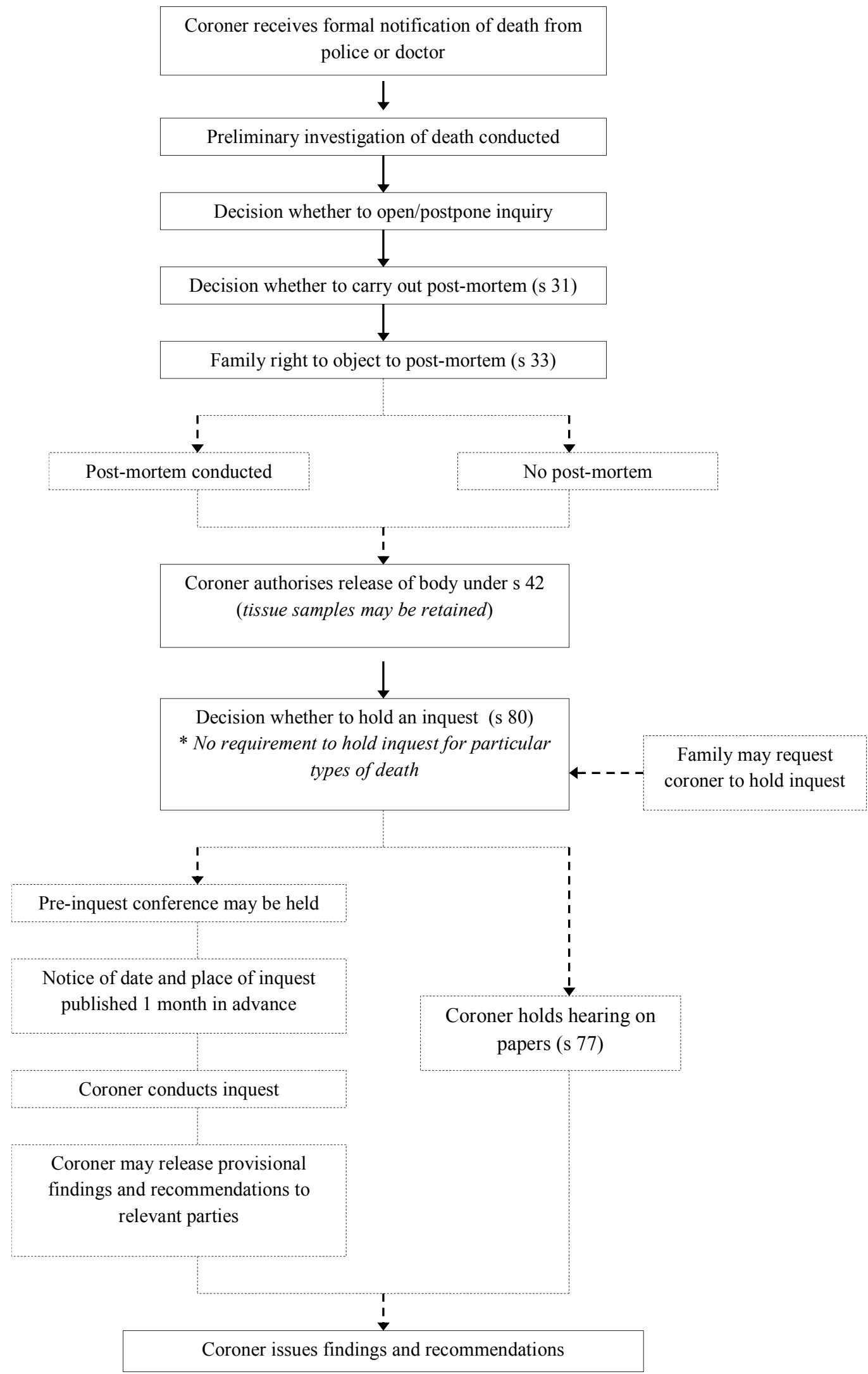


Diagram 3. Flowchart of coronial process following release of findings with author's proposed reforms

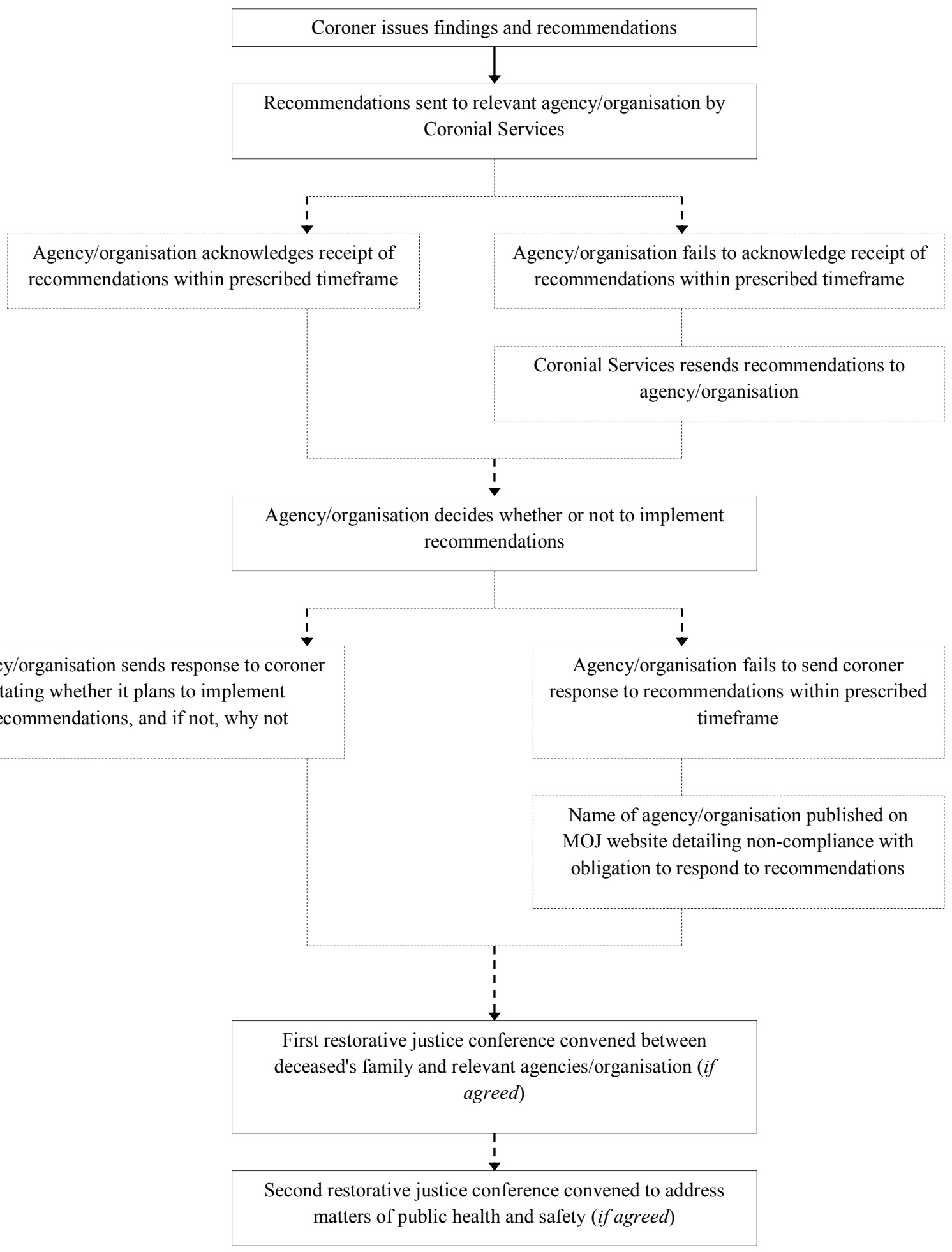




\section{Bibliography}

A Cases

\section{Canada}

People First of Ontario v Porter (1991) 5 OR (3d) 609 (Ontario Court (General Division)).

\section{New Zealand}

Berryman v Solicitor-General [2008] 2 NZLR 772 (HC).

Gravatt v Auckland Coroner's Court [2013] NZAR 345 (HC).

In the matter of an inquest into the death of Adam Barlow NZCorC Hamilton CSU2010-HAM-000021, 7 May 2012.

In the matter of an inquest into the death of Alexis Green, an infant NZCorC Christchurch CSU-2011-CCH-000961, 7 September 2012.

In the matter of an inquest into the death of Baby $J$ NZCorC Rotorua CSU-2010ROT-000045, 13 June 2012.

In the matter of an inquest into the death of Barry John Coleman NZCorC Christchurch COR13/0008, 25 March 2013.

In the matter of an inquest into the death of Bishop Pihuru Rihare Thompson NZCorC Rotorua CSU-2011-ROT-000021, 7 December 2011.

In the matter of an inquest into the death of Brian Joseph Davis NZCorC New Plymouth CSU-2010-PNO-000375, 14 December 2012. 
In the matter of an inquest into the death of Chesara Anna-Rose McMurdo NZCorC Invercargill CSU-2010-DUN-000348, 25 May 2012.

In the matter of an inquest into the death of Christopher Arepa Kahui, Infant NZCorC Auckland COR12/0019, 2 July 2012.

In the matter of an inquest into the death of Colin Arthur Moore NZCorC Whangarei CSU-2009-WHG-000105, 24 May 2012.

In the matter of an inquest into the death of Cru Omeka Kahui, Infant NZCorC Auckland COR12/0020, 2 July 2012.

In the matter of an inquest into the death of Debbie Marie Ashton NZCorC Wellington CSU-2006-WGN-000000, 19 December 2012.

In the matter of an inquest into the death of Dorothy Maxine Curtis NZCorC Christchurch CSU-2011-CCH-1089, 13 July 2012.

In the matter of an inquest into the death of Garry Keith Weeds NZCorC Whangarei CSU-2009-WHG-000045, 2 May 2012.

In the matter of an inquest into the death of Gavin George Anderson NZCorC Dunedin CSU-2012-DUN-000197, 28 January 2013.

In the matter of an inquest into the death of Glenn Richard Albert Mills NZCorC Auckland CSU-2009-AUK-001614, 17 July 2012.

In the matter of an inquest into the death of Halatau Kianamanu Naitoko NZCorC Auckland CSU-2009-AUK-000144, 23 August 2011.

In the matter of an inquest into the death of James Wilson Dodds NZCorC Rotorua CSU-2012-ROT-000308, 18 March 2013. 
In the matter of an inquest into the death of Jason Clint Martin Palmer NZCorC Auckland CSU-2010-AUK-000619, 22 August 2012.

In the matter of an inquest into the death of Jason Ross Nilsen NZCorC Invercargill CSU-2011-DUN-000123, 30 April 2012.

In the matter of an inquest into the death of John MacDonald NZCorC Christchurch CSU-2009-CCH-001149, 17 July 2012.

In the matter of an inquest into the death of Joseph James Batchelor-Smith NZCorC Invercargill CSU-2010-DUN-000346, 21 May 2012.

In the matter of an inquest into the death of Leigh Galvin McGuinness NZCorC Wellington CSU-2008-WGN-000754, 14 January 2013.

In the matter of an inquest into the death of Liam Christopher Stevenson NZCorC Dunedin CSU-2011-DUN-000211, 20 June 2012.

In the matter of an inquest into the death of Lynley Anne Burnett NZCorC Dunedin CSU-2011-DUN-000288, 26 July 2012.

In the matter of an inquest into the death of Micaela Pinkerton-Stothers NZCorC Rotorua CSU-2011-ROT-000234, 30 January 2013.

In the matter of an inquest into the death of Michael Lyndsay Grant NZCorC Invercargill CSU-2011-DUN-000173, 23 April 2012.

In the matter of an inquest into the death of Norman Bruce Thompson NZCorC Oamaru CSU-2010-DUN-000210, 13 January 2012.

In the matter of an inquest into the death of Paula Adele Jessep NZCorC Rotorua CSU-2011-ROT-000419, 30 January 2013. 
In the matter of an inquest into the death of Rakaua Rawhira Rongen NZCorC Invercargill CSU-2011-DUN-000435, 7 August 2012.

In the matter of an inquest into the death of Richard John Barriball NZCorC Balclutha CSU-2010-DUN-000364, 30 April 2012.

In the matter of an inquest into the death of Robert Blair Darry NZCorC Dunedin CSU-2011-DUN-000101, 29 June 2012.

In the matter of an inquest into the death of Robert Wilson Jarvie NZCorC Wellington CSU-2011-WGN-000196, 5 September 2012.

In the matter of an inquest into the death of Roy Middleton NZCorC Alexandra CSU2012-DUN-000021, 28 January 2013.

In the matter of an inquest into the death of Stanley Eric Turner NZCorC Dunedin CSU-2010-DUN-000310, 15 June 2012.

In the matter of an inquest into the death of Stephen Fitzgerald NZCorC Wellington CSU-2008-WGN-000310, 31 January 2013.

In the matter of an inquest into the death of Tahi Elvis Edwards NZCorC Rotorua CSU-2011-ROT-000008, 30 August 2012.

In the matter of an inquest into the death of Te Atirau Matehaere Hamiora Gerrard NZCorC Wellington CSU-2009-WGN-000163, 28 June 2012.

In the matter of an inquest into the death of Troy Macfarlane Adamson NZCorC Gore CSU-2011-DUN-000072, 25 May 2012.

In the matter of an inquest into the death of Wayne John Haaima NZCorC Oamaru CSU-2010-DUN-000456, 11 June 2012. 
In the matter of an inquest into the death of William James Keast NZCorC Gore CSU2011-DUN-000521, 13 September 2012.

In the matter of an inquest into the death of $\mathrm{Mr} P$ NZCorC Palmerston North CSU2011-PNO-000228, 2 August 2012.

In the matter of an inquiry into the death Alan Ross Wielim Jones NZCorC Hamilton CSU-2012-HAM-000320, 17 December 2012.

In the matter of an inquiry into the death Albert Alapati NZCorC Wellington CSU2012-WGN-000048, 7 December 2012.

In the matter of an inquiry into the death of Amanda Sharon Brunt NZCorC Hamilton CSU-2011-HAM-000244, 30 July 2012.

In the matter of an inquiry into the death of Antoine Roni Dixon NZCorC Wellington CSU-2009-AUK-000201, 17 April 2013.

In the matter of an inquiry into the death of Ashley Bruce Foley NZCorC Hamilton CSU-2012-HAM-000319, 23 January 2013.

In the matter of an inquiry into the death of Baby L NZCorC Wellington CSU-2008WGN-000089, 25 July 2012.

In the matter of an inquiry into the death of Baby L NZCorC Hastings CSU-2012DUN-000290, 27 August 2012.

In the matter of an inquiry into the death of Baby T NZCorC Whangarei CSU-2010WHG-000181, 28 May 2012.

In the matter of an inquiry into the death of Baby Y NZCorC Hastings CSU-2011HAS-000150, 10 July 2012. 
In the matter of an inquiry into the death of Bailey Hohepa Kinita NZCorC Palmerston North CSU-2011-PNO-000077, 28 February 2013.

In the matter of an inquiry into the death of Barry Colin Raymond Pearson NZCorC Greymouth CSU-2010-CCH-000472, 27 June 2012.

In the matter of an inquiry into the death of Blair Calvin Edwards NZCorC Christchurch CSU-2010-CCH-000609, 23 November 2012.

In the matter of an inquiry into the death of Brendon Edward Walker NZCorC Christchurch CSU-2012-CCH-000077, 28 January 2013.

In the matter of an inquiry into the death of Bruce Riddett Arnold NZCorC Auckland CSU-2010-AUK-001077, 18 June 2012.

In the matter of an inquiry into the death of Christopher Raymond Collins Short NZCorC Dunedin CSU-2011-DUN-000354, 27 September 2012.

In the matter of an inquiry into the death of Colin Ernest Torrington NZCorC Auckland CSU-2009-AUK-001065, 27 June 2012.

In the matter of an inquiry into the death of Colin Kennedy Robinson NZCorC Palmerston North CSU-2011-CCH-000677, 18 July 2012.

In the matter of an inquiry into the death of Dana Lindsay Scrivener NZCorC Greymouth CSU-2010-CCH-000688, 2 July 2012.

In the matter of an inquiry into the death of David Ian Jackson NZCorC Hastings CSU-2011-CCH-000705, 27 July 2012.

In the matter of an inquiry into the death of Elizabeth Jill Gilbertson NZCorC Hamilton CSU-2012-HAM-000275, 27 March 2013. 
In the matter of an inquiry into the death of Eng $W u$ Ong NZCorC Wanaka CSU2010-DUN-000455, 30 April 2012.

In the matter of an inquiry into the death of Gail Annette Hansen NZCorC Hastings CSU-2012-HAS-000122, 21 January 2013.

In the matter of an inquiry into the death of Gene Robert Charles Stantiall NZCorC Hamilton CSU-2011-HAM-000624, 16 May 2012.

In the matter of an inquiry into the death of Geoffrey Raymond Gill NZCorC Invercargill CSU-2011-DUN-000400, 3 August 2012.

In the matter of an inquiry into the death of Geoffrey William Druce NZCorC Hamilton CSU-2011-HAM-000568, 30 August 2012.

In the matter of an inquiry into the death of Geok Ling Phang NZCorC Wellington CSU-2009-WGN-000626, 19 March 2013.

In the matter of an inquiry into the death of Graeme Leslie Parker NZCorC Hastings CSU-2009-CCH-001030, 22 June 2012.

In the matter of an inquiry into the death of Gwenyth Elaine Kingsbury NZCorC Wellington CSU-2010-WGN-000399, 29 January 2013.

In the matter of an inquiry into the death of Hayden George McKenzie NZCorC Dunedin CSU-2011-DUN-000113, 30 April 2012.

In the matter of an inquiry into the death of Helen Erica Schofield NZCorC Auckland CSU-2012-AUK-000577, 10 December 2012.

In the matter of an inquiry into the death of Helen Froud NZCorC Christchurch CSU2010-CCH-000768, 15 January 2013. 
In the matter of an inquiry into the death of Hilary Burgess NZCorC Auckland CSU2011-AUK-001105, 31 July 2012.

In the matter of an inquiry into the death of Hori-Hau Simon NZCorC Wellington CSU-2011-WGN-000292, 27 February 2013.

In the matter of an inquiry into the death of Hurikino Dennis Luke NZCorC Christchurch CSU-2011-CCH-000030, 25 June 2012.

In the matter of an inquiry into the death of Ian George Gillon NZCorC Christchurch CSU-2009-CCH-000847, 18 May 2011.

In the matter of an inquiry into the death of Iona Faakomiti NZCorC Hamilton CSU2011-AUK-001522, 21 September 2012.

In the matter of an inquiry into the death of Jack Maynard Wiki NZCorC Whangarei CSU-2009-WHG-000270, 12 February 2013.

In the matter of an inquiry into the death of Jacquelin Pukeroa NZCorC Whangarei CSU-2008-WHG-000156, 10 February 2013.

In the matter of an inquiry into the death of Janet Dulcie Honey NZCorC Rotorua CSU-2010-ROT-000081, 19 June 2012.

In the matter of an inquiry into the death of Janine Alice Mudgway NZCorC Hastings CSU-2012-HAS-000058, 15 February 2013.

In the matter of an inquiry into the death of Jason Allan Springfield NZCorC Palmerston North CSU-2012-PNO-000447, 24 January 2013.

In the matter of an inquiry into death of $M r R$ NZCorC Palmerston North CSU-2012PNO-000151, 4 January 2013. 
In the matter of an inquiry into the death of Julian Stukenborg NZCorC Wanaka CSU-2011-DUN-000273, 30 April 2012.

In the matter of an inquiry into the death of Justin James Newton NZCorC Christchurch CSU-2010-CCH-000515, 4 January 2013.

In the matter of an inquiry into the death of Keith Graham Barnard NZCorC Wellington CSU-2010-WGN-000313, 12 September 2012.

In the matter of an inquiry into the death of Kelly Whakaneho Noema NZCorC Wellington CSU-2009-WGN-000446, 1 May 2012.

In the matter of an inquiry into the death of Liam Douglas Jackson NZCorC Hamilton CSU-2012-HAM-000321, 17 December 2012.

In the matter of an inquiry into the death of Lixia Ling NZCorC Auckland CSU-2011AUK-000272, 27 April 2012.

In the matter of an inquiry into the death of Louise Diane Reichenbach NZCorC Palmerston North CSU-2011-PNO-000076, 28 February 2013.

In the matter of an inquiry into the death of Marjory Ruth Hesselyn NZCorC Christchurch CSU-2012-CCH-000200, 18 March 2013.

In the matter of an inquiry into the death of $M r M$ NZCorC Palmerston North CSU2012-PNO-000310, 4 December 2012.

In the matter of an inquiry into the death of Mason William Roy Fraser NZCorC Dunedin CSU-2011-DUN-000314, 10 December 2012.

In the matter of an inquiry into the death of Megan Anne Uren NZCorC Christchurch CSU-2011-CCH-000967, 22 January 2013. 
In the matter of an inquiry into the death of Meryle Iris Lovell NZCorC Hamilton CSU-2011-AUK-000936, 31 August 2012.

In the matter of an inquiry into the death of Michael Gillard Taylor NZCorC Wanaka CSU-2012-DUN-000004, 13 September 2012.

In the matter of an inquiry into the death of Natalia Joy Hume NZCorC Christchurch CSU-2011-CCH-000973, 3 July 2012.

In the matter of an inquiry into the death of Natasha Marie Harris NZCorC Invercargill CSU-2010-DUN-000069, 11 February 2013.

In the matter of an inquiry into the death of Nicholas William Malcolm Burdett NZCorC Hamilton CSU-2011-AUK-000625, 26 June 2012.

In the matter of an inquiry into the death of Paul David Columba Pleydell NZCorC Wellington CSU-2011-WGN-000451, 15 January 2013.

In the matter of an inquiry into the death of Pauline Winifred Wilson NZCorC Auckland CSU-2010-CCH-000477, 22 May 2012.

In the matter of an inquiry into the death of Peter Duncan Rouse NZCorC Hastings CSU-2012-HAS-000029, 22 June 2012.

In the matter of an inquiry into the death of Phillip John Mahoney NZCorC Hastings CSU-2011-HAS-000279, 18 September 2012.

In the matter of an inquiry into the death of Pio Tuia NZCorC Wellington CSU-2010WGN-000024, 3 May 2012.

In the matter of an inquiry into the death of Poi Moy Tan NZCorC Greymouth CSU2011-CCH-001126, 28 June 2012. 
In the matter of an inquiry into the death of Rebecca Louise Stockwell NZCorC Hastings CSU-2008-CCH-000165, 29 May 2012.

In the matter of an inquiry into the death of Renee Eileen Tori McNelis NZCorC Greymouth CSU-2010-CCH-000759, 24 August 2012.

In the matter of an inquiry into the death of Richard Paul Ennis NZCorC Dunedin CSU-2011-DUN-000502, 23 January 2013.

In the matter of an inquiry into the death of Richard Warren Toneycliffe NZCorC Palmerston North CSU-2012-PNO-000209, 7 March 2013.

In the matter of an inquiry into the death of Rosalyn Sylvia Yong NZCorC Palmerston North CSU-2011-PNO-000519, 27 July 2012.

In the matter of an inquiry into the death of Scott Ian Broad NZCorC Ashburton CSU-2011-CCH-000477, 13 March 2013.

In the matter of an inquiry into the death of Shannon Robert Waaka NZCorC Hamilton CSU-2011-HAM-000558, 6 September 2012.

In the matter of an inquiry into the death of Shaun Karl Malthus NZCorC Hamilton CSU-2011-HAM-000321, 30 April 2012.

In the matter of an inquiry into the death of Susan Margaret King NZCorC Wellington CSU-2009-WGN-000055, 21 February 2013.

In the matter of an inquiry into the death of Talitauaiseaso Celeste Itamua NZCorC Auckland CSU-2010-AUK-000952, 16 January 2013.

In the matter of an inquiry into the death of TC NZCorC Palmerston North CSU2009-PNO-000260, 23 July 2012. 
In the matter of an inquiry into the death of Teresa Marlene Brine NZCorC Auckland CSU-2011-AUK-000051, 15 August 2012.

In the matter of an inquiry into the death of Timothy Edward Turner NZCorC Whanganui CSU-2009-WGN-000306, 13 September 2012.

In the matter of an inquiry into the death of Tom Lawrence Kenny NZCorC Christchurch CSU-2010-CCH-000057, 27 August 2012.

In the matter of an inquiry into the death of Tracy Janice Dando NZCorC Hastings CSU-2011-PNO-000501, 3 January 2013.

In the matter of an inquiry into the death of Trent John Durant Ashton NZCorC Timaru CSU-2012-CCH-000011, 11 January 2013.

In the matter of an inquiry into the death of Troy Alan Cullinane NZCorC Hamilton CSU-2012-HAM-000048, 6 September 2012.

In the matter of an inquiry into the death of Troy Lucius Quayle-Lindbom NZCorC Greymouth CSU-2010-CCH-000688, 2 July 2012.

In the matter of an inquiry into the death of William Stuart Dalzel McLay NZCorC Wellington CSU-2009-WGN-000189, 23 July 2012.

In the matter of an inquiry into the death of Yu-Ling Chen NZCorC Greymouth CSU2011-CCH-001127, 28 June 2012.

In the matter of an inquiry into the death of Yuniarto Heru, Samsuri, Taefur NZCorC Wellington CSU-2010-CCH-000579, 6 March 2013.

In the matter of an inquiry into the death of Yu Tong Guan NZCorC Christchurch CSU-2010-CCH-000076, 4 January 2013. 
In the matter of an inquiry into the death of Yvonne Jane McGlashan NZCorC Timaru CSU-2010-CCH-000784, 7 November 2012.

In the matter of Masani Sila NZCorC Auckland CSU-2012-AUK-000394, 31 May 2012.

Matthews v Hunter [1993] 2 NZLR 683 (HC).

Orchard v Osborne \& Anor HC Auckland M101-96, 19 July 1996.

\section{United Kingdom}

$R v$ HM Coroner for North Humberside and Scunthorpe Ex p Jamieson [1995] QB 1, [1994] 3 WLR 82 (CA).

$R v$ Inner South London Coroner; ex parte Williams [1999] 1 All ER 344, (1998) 162 JP 751 (CA).

\section{B Legislation}

$1 \quad$ Australia

Coroners Act 2008 (Vic).

Coroners Act 2003 (Qld).

\section{Canada}

Coroners Act $1990(\mathrm{ON})$.

3 New Zealand

Accident Compensation Act 2001. 
Arms Code 2013.

Civil Aviation Act 1990.

Children's Commissioner Act 2003.

Coroners Act 1951.

Coroners Act 1988.

Coroners Act 2006.

Coroners (Forms) Regulations 2008.

Coroners Ordinance 1846.

Corrections Act 2004.

Criminal Code Act 1893.

Evidence Act 2006.

Health and Disability Commissioner Act 1994.

Independent Police Conduct Authority Act 1988.

Land Transport Act 1998.

New Zealand Public Health and Disability Act 2000.

Transport Accident Investigation Commission Act 1990. 


\section{$4 \quad$ United Kingdom}

Coroners (Amendment) Rules 2008 (UK).

Coroners and Justice Act 2009 (UK).

Coroners Rules 1984 (UK).

\section{Texts and Essays in Edited Texts}

John Braithwaite "Principles of Restorative Justice" in Andrew Von Hirsch and others (eds) Restorative Justice and Criminal Justice: Competing or Reconcilable Paradigms? (Hart Publishing, Oxford, 2003) 1.

John Cooper Inquests (Hart Publishing Ltd, United Kingdom, 2011).

Ian Freckelton and David Ranson Death Investigation and the Coroner's Inquest (Oxford University Press, Melbourne, 2006).

Ian Freckelton "Expert Proof in the Coroner's Jurisdiction" in Hugh Selby (ed) The Aftermath of Death (Federation Press, Sydney, 1992) 37.

Ian Freckelton "Inquest Law" in Hugh Selby (ed) The Inquest Handbook (Federation Press, New South Wales, 1998) 1.

Geoffrey Glassock "Coping with Grief" in Hugh Selby (ed) The Aftermath of Death (Federation Press, Sydney, 1992) 186.

Boronia Halstead "Coroners' recommendations following deaths in custody" in Hugh Selby (ed) The Inquest Handbook (Federation Press, New South Wales, 1998) 186.

James Harrison and Jerry Moller "Learning from experience: towards prevention" in Hugh Selby (ed) The Inquest Handbook (Federation Press, New South Wales, 1998) 208. 
James Harrison and Daniel Tyson "Preventing Injury" in Hugh Selby (ed) The Aftermath of Death (Federation Press, Sydney, 1992) 233.

Graeme Johnstone "An Avenue for Death and Injury Prevention" in Hugh Selby (ed) The Aftermath of Death (Federation Press, Sydney, 1992) 140.

Graeme Johnstone "Coroner's inquiries and recommendations" in Hugh Selby (ed) The Inquest Handbook (Federation Press, New South Wales, 1998) 38.

Michael King and others Non-Adversarial Justice (The Federation Press, Sydney, 2009).

Stephen Penk "Thinking about Privacy" in Stephen Penk and Rosemary Tobin (eds) Privacy Law in New Zealand (Brookers Ltd, Wellington, 2010) 1.

Pauline Tapp "Privacy Issues in the Family Court" in Stephen Penk and Rosemary Tobin (eds) Privacy Law in New Zealand (Brookers Ltd, Wellington, 2010) 277.

Jack Waterford "The media and inquests" in Hugh Selby (ed) The Inquest Handbook (Federation Press, New South Wales, 1998) 52.

David B Wexler Therapeutic Jurisprudence: The Law as a Therapeutic Agent (Carolina Academic Press, North Carolina, 1990).

David B Wexler and Bruce J Winick "Introduction" in David B Wexler and Bruce J Winick (eds) Law in a Therapeutic Key: Developments in Therapeutic Jurisprudence (Carolina Academic Press, Michigan, 1996) i.

\section{Journal Articles}

Lucy Biddle "Public hazards or private tragedies? An exploratory study of the effect of coroners' procedures on those bereaved by suicide" (2003) 56 Social Science \& Medicine 1003. 
John Braithwaite "Restorative Justice and Therapeutic Jurisprudence" (2002) 38(2) Crim LB 244.

Lyndal Bugeja and David Ranson "Coroners' Recommendations: A Lost Opportunity" (2005) 13 JLM 173.

Nathalie Des Rosiers "Rights Are Not Enough: Therapeutic Jurisprudence Lessons for Law Reformers" (2002) 18 Touro L Rev 443.

Alan Fletcher "Coroners' Rule 43 reports" (2011) 17(6) Clinical Risk 217.

Ian Freckelton "Death Investigation and the Evolving Role of the Coroner" (2008) 11 Otago LR 565.

Ian Freckelton "Death investigation, the coroner and therapeutic jurisprudence" (2007) 15 JLM 1.

Ian Freckelton "Therapeutic Jurisprudence Misunderstood and Misrepresented: The Price and Risks of Influence" (2008) 30 T Jefferson L Rev 575.

Daniel Harwood and others "The grief experiences and needs of bereaved relatives and friends of older people dying through suicide: a descriptive and case-control study" (2002) 72 Journal of Affective Disorders 185.

JM Jacobstein "Some Reflections on the Control of the Publication of Appellate Court Opinions" (1975) 27 Stan L Rev 791.

Michael King "Non-adversarial justice and the coroner's court: A proposed therapeutic, restorative, problem-solving model" (2008) 16 JLM 442.

Michael King "Restorative Justice, Therapeutic Jurisprudence and the Rise of Emotionally Intelligent Justice" (2008) 32 MULR 1096.

Neil MacLean "Coronial reform and the role of the Chief Coroner" [2012] NZLJ 207. 
Innis MacLeod "The Ombudsman" (1966) 19 Admin L Rev 93.

Ron Paterson "The Patients' Complaints System in New Zealand" (2002) 21(3) Health Affairs 70.

John Petrila "A review of Essays in Therapeutic Jurisprudence" (1993) 10 NYL Sch J Hum Rts 877.

Graham Rossiter "The Coroners Act 2006" [2008] NZLJ 324.

Thomas J Scheff "Community Conferences: Shame and Anger in Therapeutic Jurisprudence" (1998) 67 Rev Jur UPR 96.

Tom R Tyler "The Psychological Consequences of Judicial Procedures: Implications for Civil Commitment Hearings" (1992) 46 SMU Law Review 433.

David B Wexler "An Orientation to Therapeutic Jurisprudence" (1994) 20(2) New Eng J on Crim \& Civ Confinement 259.

David B Wexler "Reflections on the scope of therapeutic jurisprudence" (1995) 1(2) Psychology, Public Policy, and Law 220.

Bruce J Winick "On Autonomy: Legal and Psychological Perspectives" (1992) 37 Vill L Rev 1705.

Bruce J Winick "The Jurisprudence of Therapeutic Jurisprudence" (1997) 3(1) Psychology, Public Policy, and Law 184. 


\section{E Official Sources}

\section{$1 \quad$ Australia}

Law Reform Commission of Western Australia Review of Coronial Practice in Western Australia: Discussion Paper (June 2011).

Victoria Law Reform Committee Review of the Coroners Act 1985 (Parliamentary Paper No 229 of Session 2003-2006, 14 September 2006).

\section{$2 \quad$ New Zealand}

Cabinet paper "Coroners Act Review: Proposals for Reform - Paper 1" (Ministry of Justice, 26 June 2013).

Bronwen Pelvin Letter to Coroner Matenga re Barlow inquest recommendations (Ministry of Health, Briefing Paper, 20 December 2012) (Obtained under Official Information Act 1982 Request to Ministry of Health).

Dawn Kerrison and Leo S Mortimer Response to Coroner's Recommendation in Relation to the Death of Debbie Marie Ashton (Ministry of Transport, Briefing Paper OC01467, 5 April 2013) (Obtained under Official Information Act 1982 Request to the Ministry of Transport).

Email from Al McCone (National Manager of Staff Relations \& Training, Landcorp Farming Ltd) to Elena Mok regarding implementation of coroner's recommendations following Renee McNelis inquest (2 July 2013).

Email from Andrew Hearn (General Manager of Policy, Research and Advice, Health Promotion Agency) to Elena Mok regarding coroner's recommendations made following Megan Anne Uren inquiry (24 July 2013). 
Email from Chris Allen (General Manager of City Infrastructure, Hamilton City Council) to Elena Mok regarding implementation of coroner's recommendations following Shaun Karl Malthus inquiry (31 July 2013).

Email from Gudrun Jones (Legal Counsel, Waikato District Council) to Elena Mok regarding implementation of coroners' recommendations by Waikato District Council (24 July 2013).

Email from Janice van Mil (General Manager, Cressida Group) to Elena Mok regarding implementation of coroner's recommendations by Mercy Jenkins ( 8 July 2013).

Email from Louise Jago (Communications Co-ordinator, KiwiRail) to Elena Mok regarding coroner's recommendations made following Rosalyn Sylvia Yong inquiry (12 August 2013).

Email from Michelle Higgie (Executive Assistance, Waitomo District Council) to Elena Mok regarding implementation of coroner's recommendations (5 August 2013).

Email from Karen Shirley (Legal Executive, Waikato District Health Board) to Elena Mok regarding coroner's recommendations made following Adam Barlow inquest (29 July 2013).

Email from Sean McKinley (Chief Executive, Social Workers Registration Board) to Elena Mok regarding coroner's recommendations following Alexis Green inquest ( 9 September 2013).

Email to Sharyn Forsyth and Lindsay Stuart regarding MNZ comment on PWC briefing and coroner's recommendations (23 May 2012) (Obtained under Official Information Act 1982 Request to Maritime New Zealand).

Email from Sharyn Forsyth (General Manager Maritime Services, Maritime New Zealand) regarding Lake Waihola marathons (7 June 2012) (Obtained under Official Information Act 1982 Request to Maritime New Zealand). 
Email from Shaun Barnett (Federated Mountains Club Bulletin editor) to Elena Mok regarding implementation of coroners' recommendations by Federated Mountains Club (2 August 2013).

Email from Sophie Hazelhurst (Senior Media Advisor, Maritime New Zealand) to Sharyn Forsyth and others regarding coroner's recommendations on jet ski death (16 May 2013) (Obtained under Official Information Act 1982 Request to Maritime New Zealand).

Emails regarding Power Boat Marathons on Lake Waihola (20 June 2012) (Obtained under Official Information Act 1982 Request to Maritime New Zealand).

Emails regarding policy for approving or declining a maritime event (15 January 2013) (Obtained under Official Information Act 1982 Request to Maritime New Zealand).

Emails regarding medical cover at Power Boat Races (1 February 2013) (Obtained under Official Information Act 1982 Request to Maritime New Zealand).

Henry Peach and Leo S Mortimer Response to Coroner Ian Smith's Recommendations on Cycle Safety - Questions and answers to support Minister Woodhouse's response to Coroner Ian Smith (Ministry of Transport, Briefing Paper OC01501, 15 March 2012) (Obtained under Official Information Act 1982 Request to the Ministry of Transport).

Labour Group Policy and Operating Procedures - Part 7: Coroner's finding and recommendations (Ministry of Business, Innovation and Employment, Operational Manual, 16 July 2009) (Obtained under the Official Information Act 1982 Request to Ministry of Business, Innovation and Employment).

Law Commission Coroners (NZLC R62, 2000). 
Letter from Adrian Regnault (General Manager of Building System Performance Branch, Ministry of Business, Innovation and Employment) to Elena Mok regarding coroner's recommendations following Janet Dulcie Honey inquiry (26 July 2013).

Letter from Alison Masters (Executive Clinical Director, Capital \& Coast District Health Board) to Elena Mok regarding implementation of coroner's recommendations following Gwenyth Kingsbury inquiry (19 August 2013).

Letter from Anne Tolley (Minister of Police) to Elena Mok regarding implementation of coroner's recommendations following James Dodds inquest by Police (2 September 2013).

Letter from Barry Taylor (National Manager of Operations, Police National Headquarters) to Elena Mok regarding implementation of coroners' recommendations by Police (3 September 2013).

Letter from Bernadine Mackenzie (Deputy Chief Executive, Child Youth and Family) to Elena Mok regarding implementation of coroners' recommendations by Ministry of Social Development (4 October 2013).

Letter from Bernadine Mackenzie (Deputy Chief Executive, Child Youth and Family) to Neil MacLean (Chief Coroner) regarding recommendations made following Baby Alexis inquest (31 October 2012) (Obtained under Official Information Act 1982 Request to Ministry of Social Development).

Letter from Bronwen Pelvin (Senior Advisor Maternity Services, Ministry of Health) to Gary Matenga (Coroner for Hamilton Region) regarding recommendations made following Adam Barlow inquest (20 December 2012) (Obtained under Official Information Act 1982 Request to Ministry of Health).

Letter from Bruce Sherlock (General Manager, Hutt City Council) to Elena Mok regarding coroner's recommendations following Stephen Fitzgerald inquest (18 July 2013). 
Letter from Chris Carson (Director of International Policy, Ministry for Primary Industries) to Elena Mok regarding recommendations made following Natasha Marie Harris inquest (1 August 2013).

Letter from Colin Knaggs (State Highway Manager, New Zealand Transport Agency) to Sarn Herdson (Coroner for Auckland region) regarding recommendations made following Pauline Winfred Wilson inquiry (8 October 2012) (Obtained under Official Information Act 1982 Request to New Zealand Transport Agency).

Letter from Colin Meehan (Acting General Manager of Regulatory Support and Design, Ministry of Business, Innovation and Employment) to Elena Mok regarding implementation of coroners' recommendations by Ministry of Business, Innovation and Environment (29 July 2013).

Letter from Dale Bramley (Chief Executive Officer, Waitemata District Health Board) to Elena Mok regarding implementation of coroner's recommendations following the death of Bruce Arnold (9 July 2013).

Letter from Don Mackie (Chief Medical Officer, Ministry of Health) to Elena Mok regarding implementation of coroners' recommendations by Ministry of Health ( 8 August 2013).

Letter from Ernst Zöllner (Director for Road Safety, New Zealand Transport Agency) to Elena Mok regarding implementation of coroners' recommendations by $\mathrm{New}$ Zealand Transport Agency (24 July 2013).

Letter from Gerry Brownlee (Minister of Transport) to Garry Evans (Coroner for Wellington region) regarding recommendations made following Debbie Marie Ashton inquest (11 April 2013) (Obtained under Official Information Act 1982 Request to Ministry of Transport).

Letter from Greg Brogden (Senior Corporate Solicitor, Canterbury District Health Board) to Elena Mok regarding implementation of coroners' recommendations by Canterbury District Health Board (26 July 2013). 
Letter from Julie Miller (Manager of Ministerial Services, Department of Corrections) to Elena Mok regarding implementation of coroners' recommendations by Department of Corrections (30 July 2013).

Letter from Kevin O'Kane (Principal Advisor, Operational Policy, New Zealand Transport Agency) to Coronial Services regarding coroner's recommendations made following Gavin George Anderson inquiry (14 February 2013) (Obtained under Official Information Act 1982 Request to New Zealand Transport Agency).

Letter from Kevin Woods (Director General of Health) to Sue Johnson (Coroner for Christchurch Region) regarding recommendations made following Alexis Green inquest (29 October 2012) (Obtained under Official Information Act 1982 Request to Ministry of Health).

Letter from Kevin Woods (Director General of Health) to David Crerar (Coroner for Dunedin Region) regarding recommendations made following Mason William Roy Fraser inquest (10 January 2013) (Obtained under Official Information Act 1982 Request to Ministry of Health).

Letter from Leo S Mortimer (Manager of Land Transport Safety, Ministry of Transport) to Carla na Nagara (Coroner for Palmerston North region) regarding recommendations made following Tom Lawrence Kenny inquiry (18 December 2012) (Obtained under Official Information Act 1982 Request to Ministry of Transport).

Letter from Mal Joyce (Operations Manager of Child Health Services, Capital \& Coast District Health Board) to Elena Mok regarding implementation of coroner's recommendations following "Baby L" inquiry (29 July 2013).

Letter from Mark Wogan (Manager of Energy Safety, Ministry of Business, Innovation and Employment) to Christopher Devonport (Coroner for Hastings region) regarding recommendations made following Phillip John Mahony inquiry (10 July 2013) (Obtained under Official Information Act 1982 Request to Ministry of Business, Innovation and Employment). 
Letter from Michael Woodhouse (Associate Minister of Transport) to Ian Smith (Coroner for Wellington region) regarding recommendations made following Stephen Fitzgerald inquest (22 April 2013) (Obtained under Official Information Act 1982 Request to Ministry of Transport).

Letter from Mike James (General Manager of Road and Rail, Ministry of Transport) to Elena Mok regarding implementation of coroners' recommendations by Ministry of Transport (31 July 2013).

Letter from Mike Slater (Conservator, Department of Conservation) to Elena Mok regarding coroner's recommendations made following Poi Moy Tan and Yu-Ling Chen inquest (23 July 2013).

Letter from Ona De Rooy (General Manager of Health and Safety Operations, Ministry of Business, Innovation and Employment) to Christopher Devonport (Coroner for Hastings region) regarding recommendations made following Peter Duncan Rouse inquiry (8 July 2013) (Obtained under Official Information Act 1982 Request to Ministry of Business, Innovation and Employment).

Letter from Phil Consedine (City Transportation Unit Manager, Hamilton City Council) to Peter Ryan (Coroner for Hamilton region) regarding recommendations made following Shaun Karl Malthus inquiry (15 June 2012) (Obtained under Official Information Act 1982 Request to Hamilton City Council).

Letter from Rae Hankin (Advisor, Ministry of Business, Innovation and Employment) to David Crerar (Coroner for Dunedin Region) regarding recommendations made following Geoffrey Raymond Gill inquiry (28 August 2012) (Obtained under Official Information Act 1982 Request to Ministry of Business, Innovation and Employment).

Letter from Rae Hankin (Advisor, Ministry of Business, Innovation and Employment) to Richard McElrea (Coroner for Christchurch region) regarding recommendations made following Renee Eileen Tori McNelis inquiry (13 September 2012) (Obtained 
under Official Information Act 1982 Request to Ministry of Business, Innovation and Employment).

Letter from Roger Bailey (Acting Manager State Highway, New Zealand Transport Agency) to David Crerar (Coroner for Dunedin region) regarding recommendations made following Norman Bruce Thompson inquest (12 March 2012) (Obtained under Official Information Act 1982 Request to New Zealand Transport Agency).

Letter from Sharon Girvan (Manager Government Relations, Housing New Zealand Corporation) to Elena Mok regarding implementation of coroner's recommendations following Talitauieaso Itamua inquiry (9 August 2013).

Letter from Tony Stallinger (Chief Executive of Hutt City Council) to Catherine Langman (Coronial Services Unit) regarding the Coroner's recommendation to Hutt City Council following the death of Stephen Fitzgerald (25 February 2013) (Obtained under Official Information Act 1982 Request to Hutt City Council).

Letter from Tony Ryall (Minister of Health) to Ian Smith (Coroner for Wellington Region) regarding recommendations made following Te Atirau Gerrard inquest (18 July 2012) (Obtained under Official Information Act 1982 Request to Ministry of Health).

Letter from Simon Bridges (Former Minister of Consumer Affairs) to Ian Smith (Wellington Regional Coroner) regarding the Coroner's recommendations following the death of William Stuart Dalzel McLay (2 August 2012) (Obtained under Official Information Act 1982 Request to Ministry of Business, Innovation and Employment).

Maritime New Zealand "Memorandum on Coroners Recommendations - PWC fatality" (19 September 2012) (Obtained under Official Information Act 1982 Request to Maritime New Zealand).

National Pleasure Boating Safety Minutes "25th National Pleasure Boat Safety Forum" (11 October 2012) (Obtained under Official Information Act 1982 Request to Maritime New Zealand). 
Neil MacLean "Confessions of a Coroner" (speech to New Zealand Medical Association Practice Conference and Medical Exhibition, Rotorua, June 2013).

Neonatal Abstinence Syndrome (NAS) Policy (Capital \& Coast District Health Board, GL CL-22, 28 March 2013) (Obtained under Official Information Act 1982 Request to Capital \& Coast District Health Board).

Office of the Chief Coroner of New Zealand Recommendations Recap - Issue 1 (Ministry of Justice, July 2012).

Office of the Chief Coroner of New Zealand Recommendations Recap - Issue 3 (Ministry of Justice, March 2013).

Office of the Health and Disability Commissioner Statement of Intent 2012/2015 (29 June 2012).

Rick Van Barneveld Road Level Crossing Upgrading Priority List (KiwiRail, 9 July 2013) (Obtained under Official Information Act 1982 Request to KiwiRail).

Review of Prisoner Complaints Processes (Ministry of Justice, April 2005).

Sixth Report on the Activities of the CYMRC: 1 January to 30 June 2011 (Child and Youth Mortality Review Committee, March 2012).

Terms of Reference - FRSC Caffeine Working Group (Food Regulation Standing Committee, May 2011) (Obtained under Official Information Act 1982 Request to Ministry for Primary Industries).

Beverley Wakem and David McGee Ombudsman Act Investigation of the Department of Corrections in relation to the Provision, Access and Availability of Prisoner Health Services (2012). 
Tom Watson When a Resident Medical Officer (RMO) should call the Senior Medical Officer (SMO) about inpatients under their care and about ward referrals: the principles of delegated responsibility (Waikato District Health Board, Protocol 2172, March 2009) (Obtained under Official Information Act 1982 Request to Waikato District Health Board).

\section{United Kingdom}

Brodrick Committee Report of the Committee on Death Certification and Coroners (HMSO, Cmnd 4810, 1971).

Death Certification and Investigation in England, Wales and Northern Ireland, Report of a Fundamental Review (HMSO, Cm 5831, 2003).

Ministry of Justice (UK) Guidance for coroners on changes to Rule 43: Coroner reports to prevent future deaths (14 July 2008).

The Shipman Inquiry: Death Certification and the Investigation of Deaths by Coroners (HMSO, Cm 5854, July 2003).

Wright Committee Report of the Departmental Committee on Coroners (HMSO, Cmd 5070, 1936).

\section{F $\quad$ Press Releases and Newspaper Articles}

Associated Press "Irish Jury Finds Poor Care in Death of Woman Denied Abortion" New York Times (online ed, New York City, 19 April 2013).

Kurt Bayer "Govt needs to move on butane abuse - coroner" The New Zealand Herald (online ed, New Zealand, 25 July 2013).

Shane Cowlishaw "Coroners' powers may be boosted" Stuff.co.nz (1 August 2012).

"Coronial recommendations 'die in ditch' - judge" TVNZ (13 May 2012). 
Andres Jauregui "Soft Drink Warning Labels Face Criticism After Coroner's Finding On Natasha Harris' Coca-Cola Habit" Huffington Post (online ed, New York City, 19 February 2013).

Joanne Carroll "Official road improvement ideas get lost or ignored" The New Zealand Herald (online ed, New Zealand, 19 February 2012).

Lane Nichols "Key Kahui recommendation ignored in new abuse paper" The New Zealand Herald (online ed, New Zealand, 11 October 2012).

Office of the Minister for Courts "Coroners Act Review Announcement" (press release, 26 June 2013).

Rosemary McLennan "Media barrier Krystal's legacy" Stuff.co.nz (21 October 2011).

Nick Perry "2-gallon a day cola habit linked to woman's death" NBC News (online ed, New York City, 13 February 2013).

"Cycling group opposes mandatory high-visibility clothing" (15 February 2013) Radio New Zealand News <www.radionz.co.nz>.

"Iwi seek to save future leaders from suicide" Radio New Zealand News (online ed, New Zealand, 28 August 2013).

New Zealand Police "Police respond to IPCA report into death of Halatau Naitoko" (media statement, 3 April 2012).

Laura Smith-Spark and Peter Taggart "Husband testifies his wife died after abortion was denied in Ireland" $C N N$ (online ed, international edition, 8 April 2013).

Vomie Springford "Baby's death prompts coroner warning" Wairarapa Times-Age (online ed, Wairarapa, 23 May 2013). 
Georgina Stylianou "Research into coroners' recommendations" Stuff.co.nz (15 May

University of Otago "Otago law researchers suggest changes to improve Coroners' recommendations" (media statement, 5 August 2013).

Mike Watson "Plea not to let coroners' rulings wither" Stuff.co.nz (22 March 2013).

\section{G Internet Resources}

Courts of New Zealand "Judicial Decisions of Public Interest" $<$ www.courtsofnz.govt.nz $>$.

David Farrar "Another daft Coroner recommendation" (15 February 2013) Kiwiblog $<$ www.kiwiblog.co.nz>.

David Farrar "Coroner recommendations" (18 February 2013) Kiwiblog $<$ www.kiwiblog.co.nz>

Health Quality and Safety Commission "New Zealand Our Programmes - Mortality Review Committees" <www.hqsc.govt.nz>.

Hilleke "Another 'no brainer' Coroner's report (February 2013) Cycling in Wellington $<$ www.cyclingwellington.co.nz $>$.

Ministry of Justice "Coronial findings of public interest" <www.justice.govt.nz>.

Ministry of Justice "Summary of submissions on the targeted review of the Coroners Act 2006" (26 June 2013) <www.justice.govt.nz>.

National Coronial Information System "About NCIS" <www.ncis.org.au>.

National Coronial Information System "NCIS - Frequently Asked Questions" $<$ www.ncis.org.au>. 
Barbara Wright "The Role of the SUDI Referral Advisor" Whakawhetu - National SUDI Prevention for Māori <www.whakawhetu.co.nz>.

\section{H Other Sources}

Letter from Dean Skachill (Business Services Manager of Specialist Courts, Ministry of Justice) to Elena Mok regarding a request for copies of coroners' findings (4 July 2013).

Letter from Dean Skachill (Business Services Manager of Specialist Courts, Ministry of Justice) to Elena Mok regarding referral processes in place for notifying interested parties about coroners' recommendations (31 July 2013). 